\title{
The Effect of Ethanol on the Neuronal Subserving of Behavior in the Hippocampus
}

\author{
Yuri I. Alexandrov,2, Yuri V. Grinchenko ${ }^{1,2}$, Diana G. Shevchenko", \\ Robert G. Averkin ${ }^{3}$, Valentina N. Matz ${ }^{4}$, Seppo Laukka ${ }^{5}$, Mikko Sams ${ }^{6}$ \\ ${ }^{1}$ V. B. Svyrkov Laboratory of Neural Bases of Mind, Institute of Psychology, \\ Russian Academy of Sciences, Moscow, Russia \\ ${ }^{2}$ Department of Psychophysiology, Faculty of Psychology, State Academical University of \\ Humanitarian Sciences, Moscow, Russia \\ ${ }^{3}$ Research Group for Cortical Microcircuits of the Hungarian Academy of Sciences, Department of Physiology, \\ Anatomy and Neuroscience, University of Szeged, Szeged, Hungary \\ ${ }^{4}$ Laboratory of Morphology of the Central Nervous System, Institute of Higher Nervous Activity and Neurophysiology, \\ Russian Academy of Sciences, Moscow, Russia \\ ${ }^{5}$ Learning Research Laboratory (LearnLab), University of Oulu, Oulu, Finland \\ ${ }^{6}$ Brain and Mind Laboratory, Department of Biomedical Engineering and Computational \\ Science (BECS), Aalto University School of Science, Helsinki, Finland \\ Email: yuraalexandrov@yandex.ru
}

Received October 25, 2012; revised November 26, 2012; accepted January 3, 2013

\begin{abstract}
We have previously shown that both acute and chronic ethanol treatment depresses neural activity, specifically in the cingulate cortex. Minor influences were found in the motor cortex. The acute effect of ethanol in the hippocampus was intermediate to those in the cingulate and motor cortices. In the present study, we concentrate on the chronic effects of ethanol on the hippocampus. We demonstrate how the neuronal activity underlying food-acquisition behavior is modified after chronic ethanol treatment, and how the hippocampus subserves formation of newly-formed alcohol-acquisition behavior. Neuronal activity in CA1 was more sensitive to chronic ethanol than the Dg area. Acute administration of ethanol had a normalizing effect on the chronically-treated animals: their performance and the hippocampal neural activity approached a normal range. The sets of neurons involved in food-acquisition behavior formed before chronic ethanol treatment, and those involved in alcohol-acquisition behavior formed after treatment significantly overlapped supporting the view that the neuronal mechanisms of pre-existing behavior provide the basis for the formation of new behavior. Additionally, we also discovered alcohol-acquisition selective neurons. Assuming that the formation of new neuronal specializations underlies learning, we believe that alcohol-selective neurons are specialized during the formation of alcohol-acquisition behavior. Our data demonstrate several new findings on the effect of acute and chronic ethanol on hippocampus activity, and how the neuronal activity relates to behavior before and after ethanol treatment.
\end{abstract}

Keywords: Neuronal Activity; Learning; Memory; Place Cells; CA1; Dg; Alcohol; Morphology

\section{Introduction}

The hippocampus is intimately involved in memory, learning and spatial cognition [1] (p. 148; see also in: [2-9]; and others). It is very sensitive to alcohol intoxication [10-12] since ethanol selectively influences hippocampal neurotransmitter systems $[6,13,14]$. The amnesic effects of ethanol administration are qualitatively similar [6] (p. 122) to those found after hippocampal damage [15]. Ethanol is therefore a useful tool to study the role of the hippocampus in memory systems [16].

Accumulating data suggest that there is a strong similarity between the neuronal mechanisms underlying the formation of long-term memory during learning and "long-lived adaptation" arising during chronic exposure to addictive substances [17-20]. Cyclic-AMP response element-binding protein (CREB) and immediate-early genes are important components of the switch from shortterm to long-term memory [21-24]. Evidence of the activity of these genes has also been found in a variety of long-term adaptive changes in the brain, such as alcohol abuse, to switch from short-term modifications in healthy individuals to a long-term addiction. Understanding mechanisms of such switches is important and requires more studies [17-19].

In our studies of acute ethanol effects on neural activity, we have analyzed behavioral specialization of neu- 
rons. Ethanol has a selective influence on various brain structures and even on neighboring neurons [25-30]. This selectivity has been suggested to be due to various functional and structural factors, each of which can predict the effect of ethanol on a particular brain site, but fail to do so on another site [31]. We have suggested that the critical factor, though not unique, is the behavioral specialization of neurons, i.e. their belonging to a particular functional system [32-36] underlying behavior.

We consider the formation of a new system as fixation of the stage of individual development - the formation of a new element of memory during learning. The neural basis of this process is the specialization of "reserve" (silent) neurons (and probably new neurons appearing in neoneurogenesis) but not a change in specialization of already specialized units. A new system is added to the existing elements of memory. Newly formed systems do not substitute the previously formed ones, but are "superimposed" on them. Research in our laboratory has demonstrated that complex instrumental behavior is realized by new system that was formed during the learning of the acts composing this behavior, and by the simultaneous realization of older systems, formed at previous stages of individual development. The latter may be involved in many behavioral patterns, i.e. they belong to elements of memory that are common for various acts. Therefore, the realization of particular behavior is the realization of the history of its development. Multiple systems, each fixing a certain stage of development of the given behavior, are involved (see in [33-36]).

In our previous studies, different types of neuronal specializations were identified in various brain areas of freely moving rabbits and rats that were performing instrumental food-acquisition behavior in an operant cage equipped with two pedals and two feeders [23,31,33-49]. Specializations can be classified in two main categories. "SE-neurons" which are activated in relation to comparatively new behavioral acts formed during an animal's learning in the operant chamber (i.e. in relation to specific elements of the operant task: approaching the feeder, taking food from the feeder, approaching the pedal, pressing the pedal). Their activation is selectively related to a certain behavioral act, but is independent of its detailed motor execution. "NSE-neurons" are activated in relation to non-specific elements of the behavioral task; their activation is related to a certain movement (e.g. turning left or right). They are activated during an identical movement that can be performed in different behavioral contexts. "U-neurons" (undefined) do not show consistent activation during the given task, i.e. their specialization is unknown.

Our classification is compatible with other neuronal property classifications (see [42]) and corresponds well to the multitude of facts revealed in various species dur- ing investigation of cortical and subcortical unit activity. In behaving animals, NSE-neurons as well as SE-neurons can be found [50-59]. We have used this classification in investigation of neuronal mechanisms of formation and realization of behavior, including the correlation of immediate-genes expression with neurons specializations, for comparative investigations of neuronal subserving of instrumental behaviors in different species, for the study of effects of local brain damage, and acute and chronic ethanol administration [23,24,31,33-49,60-62].

In our previous studies, we have analyzed the activity of 1226 neurons in different layers of the posterior cingulate cortex, the anterolateral motor cortex and in different regions of the hippocampus (CA1 and DG) of freely moving healthy rabbits $[31,40,42]$. We concluded that behavioral specialization is the main determinant of the influence of ethanol [42]. We found that in the posterior cingulate cortex, acute ethanol administration (1 $\mathrm{g} / \mathrm{kg}$; i.p.) selectively and reversibly depressed the activity of many SE-neurons. There were no changes in the pattern of neuronal behavioral specializations (the numerical relation between neurons belonging to the different types of behavioral specialization: SE-, NSE-, and U-neurons) in the motor cortex. The hippocampus was in an intermediate position. The same direction of ethanol effects was found as for the cingulate cortex; the number of certain kinds of SE-neurons (mostly complex-spike cells) decreased, and that of NSE-neurons increased, but there was no significant change in the relative number of SE- and NSE-neurons as a whole. Interestingly, using data showing attenuation of stress-induced c-fos expression by acute ethanol injection in different brain structures ([63], see review [64]), we can also conclude that ethanol influenced many brain structures, but the cingulate cortex and the hippocampus are especially sensitive.

Similar suppressive effects on SE-neurons (including classical place cells) were obtained when ethanol was applied via microdialysis on the hippocampal neurons of behaving rats [65]. Steffensen and Henriksen [66] showed that ethanol $(1.2 \mathrm{~g} / \mathrm{kg})$ suppressed the activity of the principal cells in the dentate gyrus and CA1, but not of the interneurons in these regions. However, Yan et al. [67] recently showed that for some types of CA1 interneurons (SO interneurons) ethanol enhances, and for others (SLM interneurons) it decreases the spontaneous activity. Additionally, White and Best [10] showed that acute injection of ethanol reversibly eliminates spatially specific activity of place-cells in the CA1 of the hippocampus. They proposed that a decrease in place-cell firing could impair the navigation capacity of animals. An increased sensitivity of relatively new brain systems to ethanol was also demonstrated in nestlings [41] and humans [44].

Chronic ethanol treatment also has selective effects on neurons [68-70]. However, it has remained unclear why 
some neurons are more affected than others [68] (p. 401), [69]. We found evidence that the main target for chronic effects were SE-neurons that are especially sensitive also to acute ethanol influence $[45,47]$. Neuronal subserving of behavior and morphology were modified after nine months of ethanol treatment in the posterior cingulate cortex (due to the selective effect on SE-neurons). The modification was much more prominent than in the motor cortex, which is also less sensitive to acute effects.

In the present study, we examined the effect of ethanol on hippocampal neurons. We hypothesized that ethanol selectively influences the activity of hippocampal SEneurons. Specifically, we expected that if analogous sites are modified by acute and chronic ethanol [71,72], hippocampal modifications of neuronal subserving of behavior are smaller than those in the cingulate cortex, but stronger than in the motor cortex.

The chronic influence of alcohol includes not only the toxic effects considered above, but also the de novo formation of a new need, that of alcohol. Appearance of a new need is associated with the formation of behavior directed to the satisfaction of that need. After chronic alcoholization of animals, this need can be propped by operant alcohol-acquiring behavior (AAB). It has been suggested that the physiological substrate of alcoholic motivation mediating AAB is formed on the basis of motivations formed premorbidly; this formation leads to the reorganization of the subserving of premorbid behaviors $[73,74]$, such as food-acquisition behavior (FAB). Food and drug addictions "may share common molecular, cellular and systems-level mechanisms" [75] (p. 638). The hippocampus belongs to brain networks relevant both in the neurobiology of drug addiction and obesity [76]. Pleasure producing drugs influence those cellular and molecular mechanisms that are activated by natural rewards like food [20,75]. We hypothesized that the set of hippocampal neurons involved in supporting the premorbid and newly formed behaviors will overlap and that the modification of premorbid FAB memory correlates to the formation of $\mathrm{AAB}$ memory de novo. With this aim in mind, we studied the behavioral specialization of neurons in rabbits hippocampus trained to $\mathrm{FAB}$ and $\mathrm{AAB}$, before (FAB) and after (AAB) chronic alcohol treatment.

\section{Materials and Methods}

\subsection{Ethics Statement}

The experimental protocol was in accordance with the Council of the European Communities Directive of November 24, 1986 (86/609 EEC) and the National Institutes of Health "Guidelines for the Care and Use of Animals for Experimental Procedures" and was approved by the Russian Academy of Sciences.

We analyzed the activity of 783 neurons recorded in the dorsal hippocampus (see Figure 1) of twelve chronically ethanol treated ( 9 month treatment, see below) male adult rabbits (Orictolagus cuniculus; weight about $3 \mathrm{~kg}$ ) during the realization of complex instrumental behavior in two experiments. We also studied the effect of chronic ethanol treatment on brain morphology. The rabbits had a nutritionally adequate diet.

The animals $(\mathrm{N}=7$; results were published earlier in [42]) used in the study of acute ethanol effects on the hippocampus (male rabbits) served as weight- and agematched healthy controls. Although data from the healthy animals were obtained in a separate experiment, they can be used for comparisons with the present experiments. The same experimenters made the experiments. The age, sex and weight of the animals, the duration, and the number of experimental sessions, the room, the experimental cage, the training, the electrodes, the recording techniques, the method and routine of acute ethanol administration, and the data analysis were identical in both the control and experimental groups (details below).

\subsection{Chronic Ethanol Treatment}

During chronic ethanol treatment lasting nine months, a duration known to cause permanent structural and functional alterations of the brain and impairments of performance $[6,77]$, the animals could freely choose between ethanol ( $7 \%$ first 2 weeks, $10 \%$ later) and water permanently present in water bottles (Cemic, Finland). Instrumental alcohol acquisition behavior can be formed in rabbits after such chronic ethanol treatment $[46,48]$. When
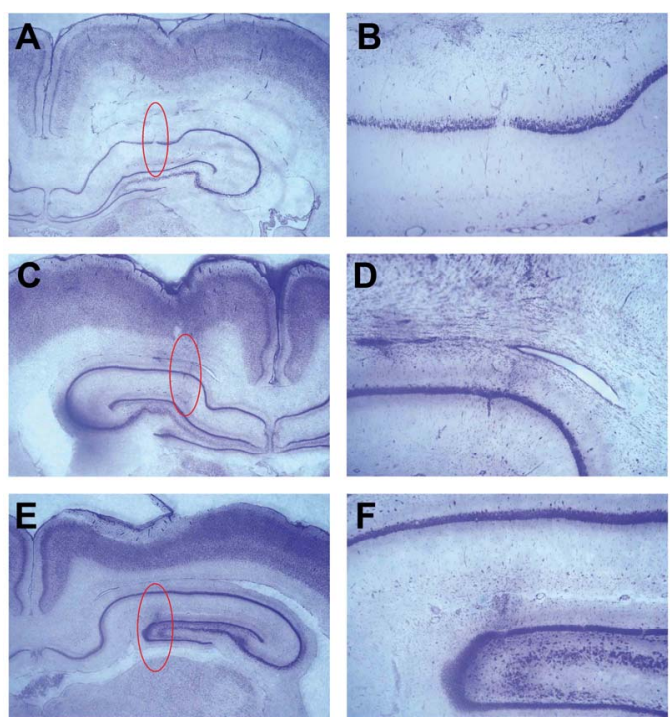

Figure 1. Localization of the electrode tracks. Photomicrographs of representative frontal slices (Nissl-stained, $20 \mathrm{mi}-$ crometers in thickness) showing the microelectrode tracks (delineated by red in A, C, and E) in CA1 (A-D) and DG (E, F). Magnification in $A, C$, and $E-12.5 \times$; in $B, D$, and $F$ $-32 \times$. 
ethanol is able to maintain operant action, dependence is supposed to have occurred [78]. In order to test the ethanol need after eighth month of the treatment, ethanol was withdrawn. After removal of ethanol for 24 hours, the diurnal consumption increased by $25 \%$ in comparison to the average amount per month. However, we have not noticed physical signs of abstinence that can rarely be observed in animals voluntarily administering the drug and are not necessary indicators of dependence $[71,72]$.

\subsection{Food-Acquisition Training}

Recording techniques, experimental cage, training, and data analysis were the same for ethanol-treated and healthy animals. They have been extensively described earlier [31,39,42,45,46,48]. Before chronic ethanol treatment, all rabbits were taught to acquire food by pressing one of the two pedals in the experimental cage (Figure 2, described in detail in [39]). Pressing of the pedal activated an automatic feeder on the same side of the cage. Each rabbit has learnt to repeatedly perform the food-acquisition task involving a constant series of acts (pressing the pedal, turning to the feeder, taking a food from the feeder, turning to the pedal) at both sides of the cage (left and right in relation to the supervising experimenter). During training and recording periods in the home cage animals received about $25 \%$ of the normal daily amount of food.

\subsection{Experiment 1}

We compared behavior and neuronal activity in E- and $\mathrm{E}+$ states (the sober state after isotonic solution administration and the state after acute ethanol administration), and also the hippocampal morphology of the control and experimental subjects. The animal subjects $(\mathrm{N}=7)$ first learned FAB and then had chronic ethanol treatment (during 9 month, see below).

In $\mathrm{E}+$ condition, the chronically treated group received ethanol by intraperitoneal injection (12\% ethanol in isotonic solution) in a dose of $1 \mathrm{~g} / \mathrm{kg}$ just before neuronal recording session, and thereafter every $1.5-2 \mathrm{~h}, 0.3-0.5$ $\mathrm{g} / \mathrm{kg}$ ethanol was added until the end of experiment (as in experiments with healthy controls). This routine allows to reach maximum of blood alcohol concentration about $0.9 \mathrm{~g} / \mathrm{l}$ (defined by gas chromatography; see [38]) 15 - 20

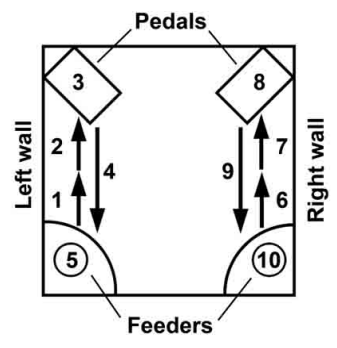

(a)

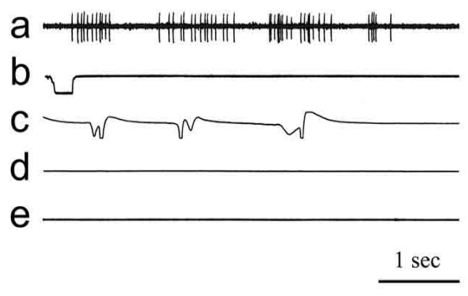

(d)

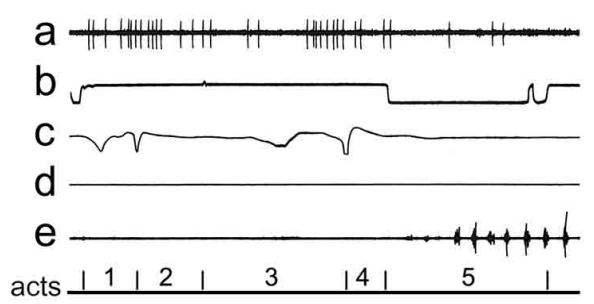

(b)

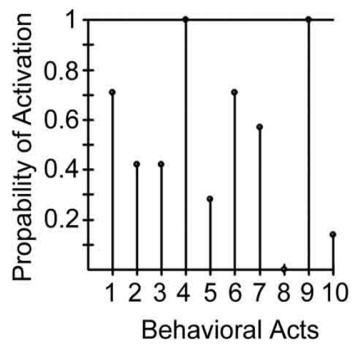

(e)

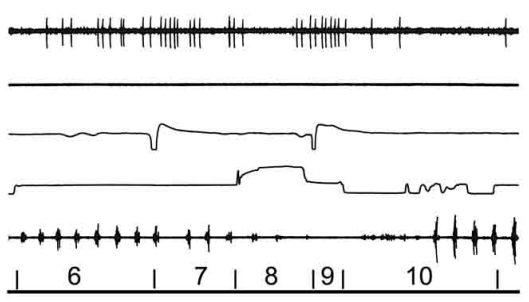

(c)

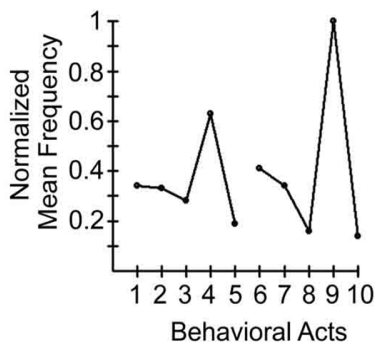

(f)

Figure 2. Schematic figure of the experimental cage and example of a NSE-neuron in CA1. The schematic figure at top left (a) shows the experimental cage and animals acts during the behavioral cycle (see Methods). The NSE-neuron was activated during food-acquisition both in left (b) and right (c) side cycles and during forced turning the animal's body by the experimenter (d). The activation appeared during turning from the feeder (act 1 and act 6 for left and right side cycles respectively; see Methods for the description of the acts), approaching the pedal, and after pedal pressing during turning from the pedal to approach the feeder (acts 4 and 9 for left and right side cycles). This neuron activated during turning the animal in any direction in horizontal plane. $a$ = neuron activity. $b=$ actrogram of behavior in the left cycle (upward deflection = pedal pressing, downward deflection = lowering head into feeder), $\mathrm{c}=$ actogram showing the position of the head in relation to either wall (left or right) of the cage between the pedal and the feeder (downward deflection = head is near middle of the wall; see Materials and methods), $d=$ actrogram of behavior in the right cycle (upward deflection = pedal pressing, downward deflection $=$ lowering head into feeder), e = EMG of $\mathrm{m}$. masseter. Numbers 1 - 10 refer to the behavioral acts, depicted in the schematic figure (a). (e) The probability of the presence of activation during the various behavioral acts. (f) Normalized mean frequency of activity during various behavioral acts. The timescale is the same for $b$, $c$, and $d$; see horizontal bar (1 sec) under $d$. 
min after the first injection and to maintain a level about $0.4 \mathrm{~g} / 1$ during the recording session. This concentration is enough to elicit changes in behavior and brain activity in rabbits, birds, and humans [36,39,41-46,48] (present results). In $\mathrm{E}-$, the equivalent amount of isotonic solution was used before and during neuronal recording session.

Same animals participated both in the E+ and E- experiments. In half of the experiments animals were tested in only one state $\left(\mathrm{E}+\right.$ or $\left.\mathrm{E}^{-}\right)$per day. The states were introduced alternatingly, thus $\mathrm{E}-$ conditions was followed by E+, and so on. In the other half of the experiments, a successful recording procedure at morning using the $\mathrm{E}-$ state was followed by another recording session at a new electrode track afternoon using $\mathrm{E}+$ state.

To make the data obtained in $\mathrm{E}+$ and $\mathrm{E}-$ experiments comparable, we had to make the animals' states similar before the experiments. Previous results from other laboratories [79], our earlier [46] and present data indicate that neither alcohol withdrawal nor acute alcohol injection brings ethanol treated animals to a "normal" healthy state. We tried to equalize animals' states before E+ and $\mathrm{E}-$ in the following way: the dose of ethanol that the subject was allowed to consume in a home cage during the night before the next experimental session depended on a previous experimental session being twofold after Ethan after $\mathrm{E}+(0.5 \mathrm{~g} / \mathrm{kg})$. As a result, the blood alcohol concentration just before recording did not differ significantly after $\mathrm{E}^{+}$and $\mathrm{E}^{-}$, and only slightly exceeded the upper limit of endogenous ethanol level in rabbits [45].

\subsection{Experiment 2}

Experiment 2 was otherwise similar to Experiment 1, except that we compared neuronal activity in two apparently similar instrumental behaviors. However, the motivation in one case was food (FAB) and in the other case ethanol (AAB). This experimental group $(\mathrm{N}=5)$ was like the first experimental group, but in addition the subjects learned $\mathrm{AAB}$ during the final part of the chronic ethanol treatment.

\subsection{Alcohol-Acquisition Training}

After the chronic ethanol treatment in Experiment 2, the same rabbits that had learned FAB before treatment were additionally taught to acquire alcohol by means of the same instrumental method in the same experimental cage. As taking solid and liquid substances is very different, we presented an ethanol solution in $0.5-\mathrm{mL}$ gelatinous capsules to make the final (consummatory) acts of FAB and AAB more similar. The highest ethanol intake during operant behavior in alcohol-preferring rats takes place at $15 \%$ concentration [80]. This is also what we found in pilot experiments, and used this concentration in capsules. After the training, we started single-unit recordings.

\subsection{Recording Techniques}

Single-unit activity was recorded in the control and ethanol experiments from the CA1 area and the dentate gyrus (Dg), in the same animals that were used for recording of posterior cingulate-cortex neurons $[45,46]$. The coordinates of recording were by AP: 4.0, ML: 3.0 4.0, DV: 3.0 - 5.0 [81]. Glass pipette microelectrodes with $2.5 \mathrm{~m} \mathrm{KCl}$, impedance of $1-5 \mathrm{MOhm}$ at $1.5 \mathrm{kHz}$ were used and driven by a manual micromanipulator [82]. During advancing an electrode, the animals occupied one of the corners near one of the feeders in rest. Below the cortex, we paid attention to the appearance of ripples [42] that were well detectable, even with the parameters of filtering that we used for single unit recording (see below). Approaching the stratum pyramidale was characterized by the appearance of complex spikes that often fired synchronously with the ripples. The activity of single cells was preamplified $(5 \times)$ and then amplified $(1000 \times)$, filtered at $300-5000 \mathrm{~Hz}$. Single cells having a spike amplitude of not less than $400-1000 \mu \mathrm{V}$ were recorded and analyzed. We were able to record high amplitude positive spikes (see Figures 3-5) that are characteristic of close to the soma (juxtacellular) recordings. EMG was recorded from m. masseter pars profundus, amplified $(100 \times)$ and filtered at $100-500 \mathrm{~Hz}$. In addition to the electrophysiological data, actographic marks of the behavior were also tape-recorded. The animals' movements from the pedal to the feeder, or vice versa, were recorded with a photocell fixed to the head of the animal, which responded to photodiodes located in the middle of the left and right walls of the cage (left and right behavioral cycles, correspondingly) between the pedal and the feeder. Rabbit behavior was video-recorded with the unit activity (audio-channel), the light indicators of the pedal pressing and head lowering, the counters of the cumulative number of spikes, and the timer. The depth of each active unit's location encountered during microelectrode penetration was measured by means of a potentiometer attached to a micromanipulator and connected with a calibrated scale showing the vertical location of the recording tip. The total number of active cells during each microelectrode penetration was counted.

\subsection{Data Analysis}

Each behavioral cycle on the left side of the cage was divided in accordance with the behavioral actographic marks into five stages (behavioral acts): 1) turning the head to the pedal; 2) approaching the pedal; 3) pressing the pedal; 4) approaching the feeder and 5) seizing food or an ethanol capsule from the feeder. The behavioral cycle on the right side of the cage was divided into analogous stages (acts 6 - 10; Figure 2). The mean frequency of spike activity of a neuron in a particular act, and the 


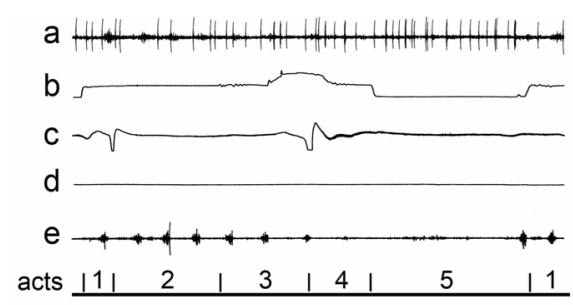

(a)

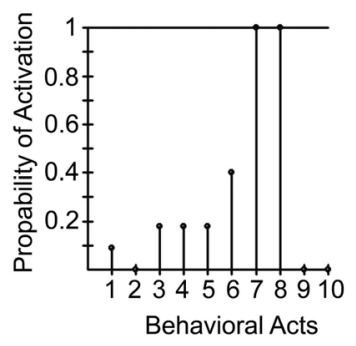

(c)

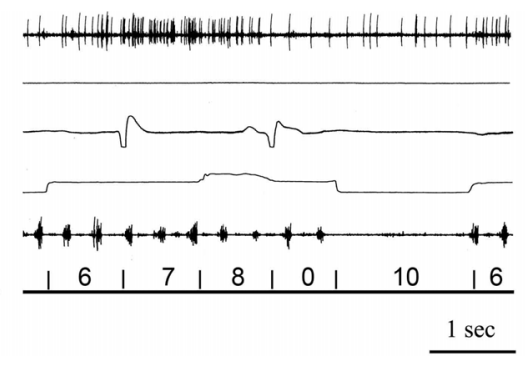

(b)

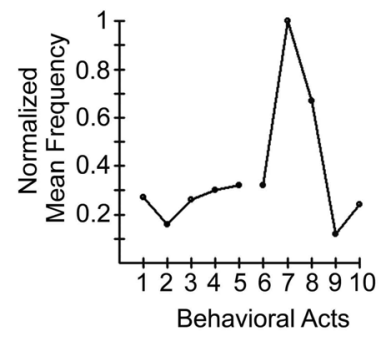

(d)

Figure 3. Example of the activity of the SE-neuron in DG. The neuron had "specific" activation only in the right-sided food-acquisition cycles. (a and b) details as in Figure 2. The neuron activated during approaching and pressing the right pedal (b, acts 7 and 8), but not the left pedal (a, acts 3 and 4). (c and d) details as in Figure 2. Note that activations of the neuron were observed in all realizations of acts 7 and 8 .

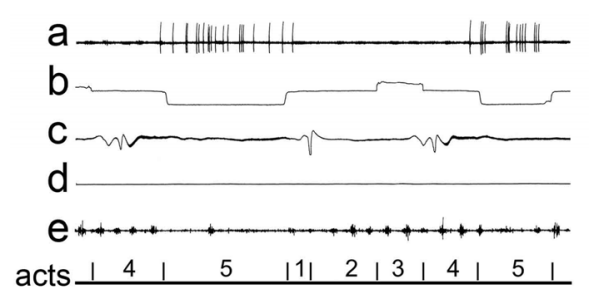

(a)

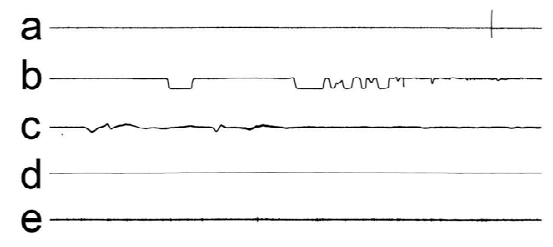

(c)

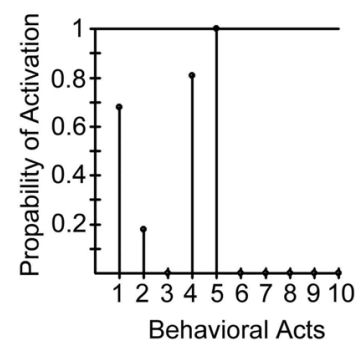

(e)

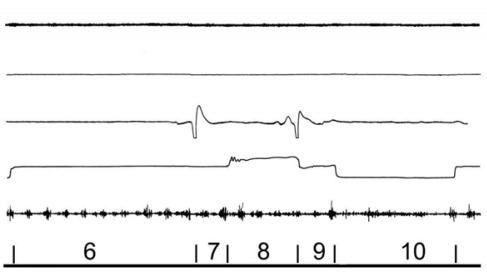

(b)

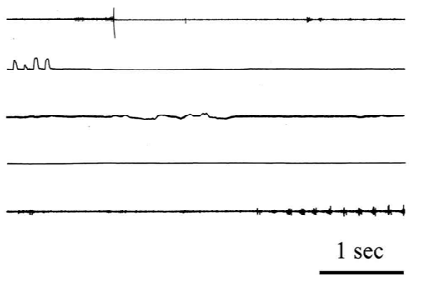

(d)

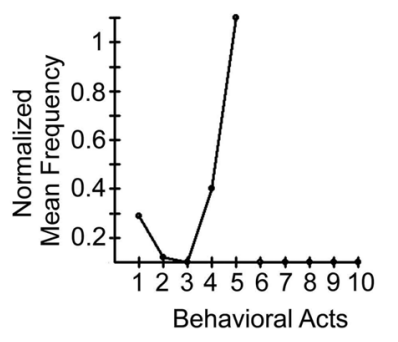

(f)

Figure 4. Example of the activity of the SE-neuron in CA1. The neuron had "specific" activation only in the left-side foodacquisition cycles. Details as in Figure 2. The neuron activated during approaching and taking the piece of food from the left feeder (a), but not from the right feeder (b) and not from the floor of the experimental cage (d). The neuron remained silent when the animal searched for a piece of food in the empty feeder (c). (e, f) Activations of the neuron were observed in all realizations of act 5 . 


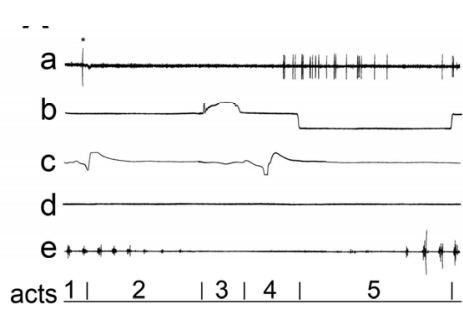

(a)

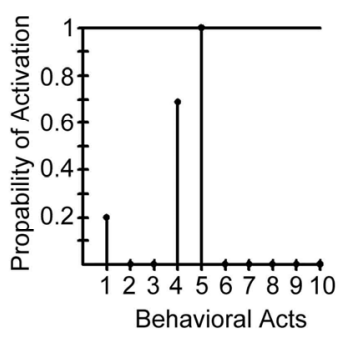

(d)

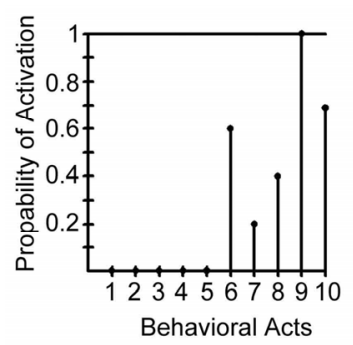

(h)

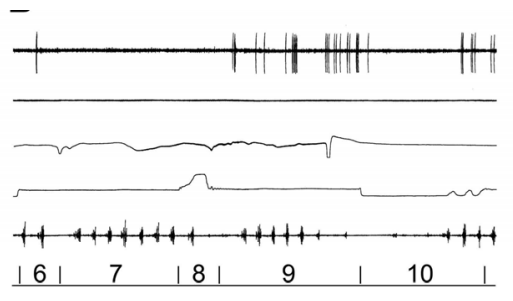

(b)

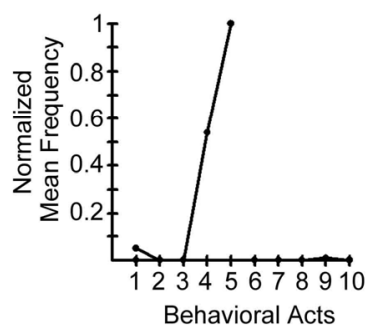

(e)

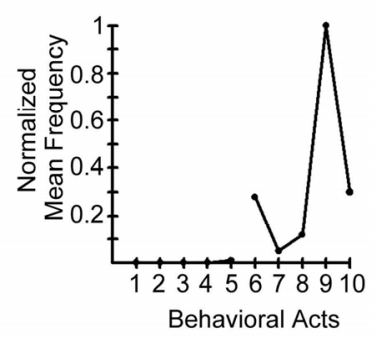

(i)

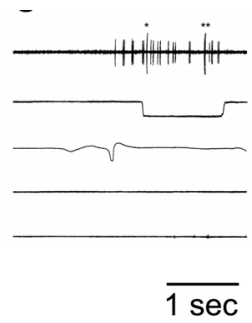

(c)

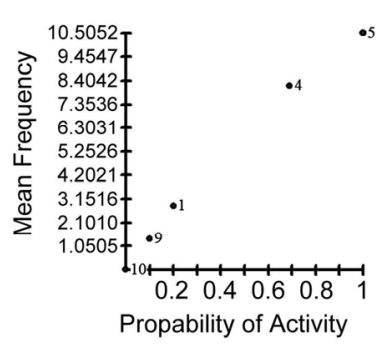

(f)

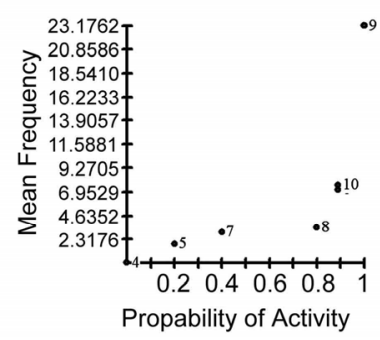

(j)

Figure 5. Example of the activity of two simultaneously-recorded SE-neurons in DG. The first neuron had "specific" activation only in left side food-acquisition cycles (a) during lowering the head to the feeder (act 5). The cell activated also during approaching the feeder and lowering the head to the feeder when it was empty (c). The second neuron had "specific" activation only in right side food-acquisition cycles (b) during turning from the pedal toward to the feeder and during approaching the feeder (act 9). The neuron was slightly active when the animal lowered the mouth to the feeder (act 10) and when it lifted it up (act 6). The neuron fired with 3 spikes during approaching the left feeder when it was empty (c). The spikes of this neuron are indicated by asterisks $\left(^{*}\right)$. (d, e) Probability of activation and normalized mean frequency of activity of one neuron and that of the other (g, h). (f, i) The probability of occurrence of any spike activity (including those not reaching the criterion of activation) during the various behavioral acts of these two neurons.

probability of activation in the act were calculated. The average frequency of activity for the entire recording was also calculated for each neuron.

The indicator of activation was taken to be when the frequency of an activity in one or several acts exceeded by a factor of no less than 1.5 the average frequency of the activity of a neuron over the whole recording period.

A neuron was considered to be specialized relative to a system of specific behavioral acts if its activation during this act was observed in all cases.

Graphs were used to describe the activity of the neuron in each act of the behavior being studied over the course of the entire period of recording, and to determine its specialization they were plotted for all of the neurons analyzed. The significance of the differences of the unit activity in the acts was determined using Student's ttests.
The units were divided into two groups: unidentified (U-neurons, no consistent activation during the behavioral cycles of instrumental behavior), and specialized in relation to the systems of behaviors under study (activated in constant relation to a certain stage of the repeated behavioral cycle). The latter group was further divided into two groups with different behavioral specialization: NSE-and SE-neurons (defined in the introduction to this paper). NSE-neurons that showed activation in relation to a particular movement of the body, head or lower jaw were considered to be specialized relative to the comparatively old systems formed earlier in individual development $[33,36]$. Whether their activation appears or not was related specifically to a certain movement, but independent of its behavioral context. Activation appeared during the same movement in different behaviors, e.g. turning to the right when approaching the feeder on one 
side of the cage, or approaching the pedal at the opposite side of the cage. SE-neurons showed activation in relation to novel behavioral acts established late in individual development, such as during the animal's learning in the experimental cage (e.g. approaching the feeder, approaching the pedal, pressing the pedal). Whether their activation appears or not was specifically related to a certain behavioral act, but independent of its motor characteristics. Similar activity was elicited when the animal pressed the pedal with the left paw, right paw or both. Many of the SE-neurons became active only when the animal pressed a certain pedal, say in the left but not in the right behavioral cycle. In the activity of such neurons, a "specific" phase may be distinguished - expressed activation; this appears during that behavioral act, in relation to a system in which these neurons were specialized. This activation usually greatly exceeds the "non-specific" activity of this neuron recorded during other behavioral acts; furthermore, "non-specific" activity is more variable and appears not in all cases. The behavioral specialization of a neuron is its permanent characteristic (see in [34-36]; and also the discussion section of this paper). Hence, "specific" neuronal activity can serve as an index for the actualization of a certain system, and the "non-specific" activity of a neuron, as we have shown earlier theoretically and empirically $[31,35,42,46]$, may indicate the specific system's retrieval from memory during performance of other "non-specific" behavioral acts. That is to say "non-specific" activity reflects an intra-memory relationship between the system to which a given neuron belongs and other systems. There are also facts indicating that even very variable discharges are not "neural noise", but signs of the neuron's involvement in the organization of behavior $[83,84]$.

\subsection{Morphological Analysis}

After the experiments, the rabbits were sacrificed with an overdose of Nembutal, and the brains were fixed in $10 \%$ formalin solution. Serial frontal slices were prepared (thickness $10-20 \mu \mathrm{m}$ ) and every 10th section was stained using the Nissl method. The brains of the healthy control and ethanol treated animals (Experiments 1 and 2) were analyzed qualitatively and quantitatively with a light micro scope ("Cytopan", Austria). The thickness of different hippocampal layers was measured in the hemisphere contralateral to the site of the microelectrode recording in coordinates corresponding to the position of the microelectrode track (see Figure 1). The location of the units in CA1 or Dg was determined on the basis of micromanipulator readings and this analysis.

The density of neurons complicated the determination of the number of pyramidal or granular cells by direct visual counting. Thus, we measured the size of each layer from the alveus to the lower arm of stratum granulosum of fascia dentata. The calculations were taken for each animal on five slices using an ocular-micrometer at 70fold magnification. However, it was necessary to count the number of cells in the CA3 hilar because of some conflicting data observed during studying it (c.f. Results). The numerical density of neurons (in a grid with square sides of $160 \times 65 \mu$ ) was determined; calculations were done in 10 visual field/slice using 5 slices per animal. The size of neurons (50 neurons from each animal) was measured at 945 -fold magnification so that we determined the maximal and minimal mutually perpendicular diameters $(a, b)$ of the cell and the square was calculated using the formula $\pi / 4 a b$.

\subsection{Statistics}

The $\chi^{2}$ test, two tailed t-test, exact Fisher criterion and canonical discriminant function analysis (c.f. Results for the description) were used in data analysis with a significance level set at $\mathrm{p}<0.05$.

\section{Results}

\subsection{Experiment 1}

During chronic ethanol treatment, the number of days when the animals consumed more water than ethanol decreased from $18 \%$ during the first 2 months to $4 \%$ within 6 - 9 months. Alcohol consumption increased during the first 2 months from $3.8 \pm 0.2$ (mean \pm S.E.M.) to $4.4 \pm$ $0.2 \mathrm{~g} / \mathrm{kg} /$ day $(\mathrm{t}=2.56, \mathrm{p}<0.05)$. Thereafter, consumption gradually decreased, and at the end of the chronic ethanol treatment, the consumption was $2.7 \pm 0.2 \mathrm{~g} / \mathrm{kg} /$ day. A similar reduction after eight-months of treatment has been observed in rats and is related to the decreased tolerance, characteristic of the late stages in the development of alcoholism [85].

\subsubsection{The Effect of Chronic Ethanol Treatment on the Pattern of Neuronal Behavioral Specializations}

We analyzed the activity of 381 hippocampal neurons (168 in CA1 and 213 in Dg) of ethanol treated rabbits. 194 neurons were analyzed in $\mathrm{E}-$ (98 in CA1 and 96 in $\mathrm{Dg}$ ) and 187 in $\mathrm{E}+$ condition (70 in CA1 and 117 in Dg). The results were compared with the activity of 303 neurons (177 in CA1 and 126 in Dg) of the control animals, 152 of them in $\mathrm{E}-(102$ in CA1 and 52 in $\mathrm{Dg}$ ) and 151 in E+ condition (75 in CA1 and 76 in Dg). NSE- and SEneurons were found both in ethanol treated animals and in healthy ones. As was shown earlier for the healthy control animals, in chronically treated animals the great majority (93\%) of SE neurons may be classified as complex spike neurons. $79 \%$ of NSE-neurons were classified 
as simple spike displace units or theta units. Thus, SEand NSE-units may be compared to projectional pyramiddal and granular neurons, or short-axon non-pyramidal interneurons, correspondingly (for details of the relationship of the classification of neurons used here and of that based on morphological, electrophysiological and functional properties of hippocampal cells, c.f. [42]).

Figure 2 shows an example of NSE-neuron activity. This neuron became activated during horizontal turning of the animal in different behavioral contexts: in the left and right cycles of the FAB while approaching both pedals and feeders (b, c) and while turning the animal's body by the experimenter (d). Figures $\mathbf{3}$ and $\mathbf{4}$ show examples of SE-neuron activity. One of them was activated during approaching and pressing the right (3b), but not the left (3a) pedal. The other was activated only during approaching and taking food from the left (4a) but not from right (4b) feeder. It was silent seizing food from the cage floor (d) and while searching for food in the empty feeder (c). Sometimes it was possible to record activity simultaneously from two SE-neurons that clearly differed in action potential amplitude or polarity. Such a pair of cells that have "specific" activations during acts of taking food near opposite walls is depicted in Figure 5.

Importantly, the pattern of behavioral specialization observed in $\mathrm{E}-$ condition changed after chronic ethanol treatment. The relative numbers of SE-, NSE- and Uneurons $(15 \%, 9 \%, 76 \%)$ in ethanol treated animals were statistically different $\left(\chi^{2}=7.08 ; \mathrm{df}=2 ; \mathrm{p}<0.05\right)$ from those in control animals $(20 \%, 16 \%, 64 \%)$. This difference was significant in CA1 $\left(\chi^{2}=6.47\right.$; df $\left.=2 ; \mathrm{p}<0.05\right)$ but not in Dg. An increase in the proportion of U-neurons $(12 \%)$ was especially prominent $\left(\chi^{2}=6.10 ; \mathrm{df}=1 ; \mathrm{p}\right.$ $<0.02)$. Again, it was significant in CA1 $\left(\chi^{2}=4.14\right.$; $\mathrm{df}=$ $1 ; \mathrm{p}<0.05)$, but not in Dg. Nevertheless, the absolute number of U-neurons increased in both structures in ethanol treated animals. We examined this using the statistical method we employed earlier $[31,42,45]$.

Taking into account the number of active units observed in the microelectrode tracks during penetration, we predicted the number of U-neurons, assuming that this number would remain constant when the total number of active units in the structure changed. This expected number of U-neurons exceeded the observed number significantly both in CA1 $\left(\chi^{2}=11.79\right.$; $\mathrm{df}=1 ; \mathrm{p}<$ $0.001)$ and in $\operatorname{Dg}\left(\chi^{2}=27.66 ; \mathrm{df}=1 ; \mathrm{p}<0.0001\right)$. Among the U-units, the proportion of neurons with slow $(<1 / \mathrm{sec})$ background frequency (determined as the mean frequency of those discharged during the behavior cycles) was significantly increased $\left(\chi^{2}=5.06 ; \mathrm{df}=1 ; \mathrm{p}<0.05\right)$ in the ethanol treated animals. This increase was evident and significant both in CA1 $\left(\chi^{2}=5.31 ; \mathrm{df}=1 ; \mathrm{p}<0.05\right)$ and $\operatorname{Dg}\left(\chi^{2}=20.39 ; \mathrm{df}=1 ; \mathrm{p}<0.0001\right)$.

The proportion of NSE-neurons increased in CA1, but not in $\mathrm{Dg}$, in ethanol treated animals from $6 \%$ (healthy) till $17 \%\left(\chi^{2}=4,26 ; \mathrm{df}=1 ; \mathrm{p}<0.05\right)$. Therefore, in ethanol treated animals proportions of SE- and NSE-neurons, that were equal in control animals $(18 \%$ and $17 \%)$, become significantly different $\left(16 \%\right.$ and $6 \% ; \chi^{2}=4.54 ; \mathrm{p}<$ $0.05)$.

The relative number of SE neurons that were highly selective and active during approaching and/or pressing the pedal near one wall of operant cage but not near the opposite wall was significantly smaller in the ethanol treated $(3 \%)$ than in the control animals $(7 \%$; exact Fisher criterion, $\mathrm{p}<0.05)$.

We carried out additional tests for 13 SE-neurons (whose activity was clearly place selective and the spike amplitude was stable enough after completion the standard program) in ethanol treated animals and for 14 units in the control rabbits to reveal if they have classical "place" fields (see [86]). 10 cells in the first animal group and 12 in the second were classified as "place" units, i.e. units which were only activated when the rabbit was located in a certain place within a varying behavioral context (see also [36,42]). Figure 6 shows that the neuron was activated near the right (b) but not the left pedal (6a) corner during FAB, while approaching the right corner without pedal pressing (4c), and when there was displacement of the animal in the same place by the experimenter. The rest of the cells showed activations related to a given place in the cage only in certain behavioral conditions. The behavioral dependence of place related activity in some hippocampal cells $[42,58,87]$, and the possibility for hippocampal principle cells being activated by internal memory cues related to behavioral results [88-90] has been demonstrated earlier. The quantitative relationship between these two subgroups of cells remained constant after ethanol treatment.

\subsubsection{The Effect of Chronic Ethanol Treatment on the Hippocampal Morphology}

Chronic ethanol treatment did not produce visible alterations in the structure of pyramidal or granular cells. No dark-stained cells, microvacuolation or shrinkage of the cytoplasm were observed. Earlier Bengoechea and Gonzalo [91] have reported an absence of any change in size of the nuclei of hippocampal neurons in patients with chronic alcoholism. However, some measures related to the size of layers and cell bodies in our experiments showed significant changes. Canonical discriminant function analyses revealed that five indices of cell morphology are sufficient for successful classification of neurons from ethanol treated and from healthy animals (Table 1). In this subset, $94 \%$ of the original grouped rabbits were correctly classified (except for one rabbit that was classified as healthy though chronic).

To estimate the reliability of classification a cross-vali- 


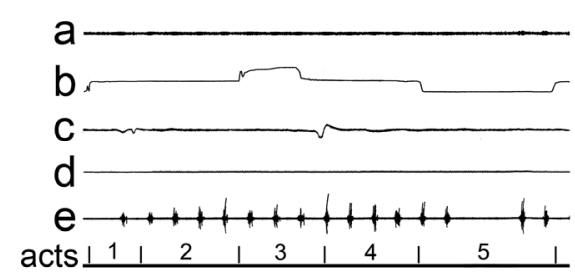

(a)

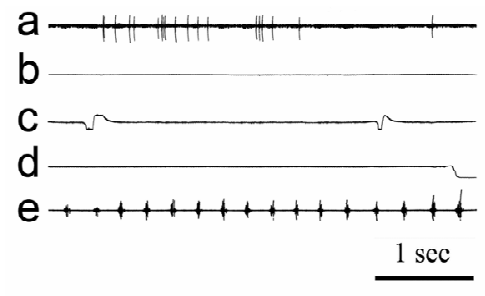

(c)

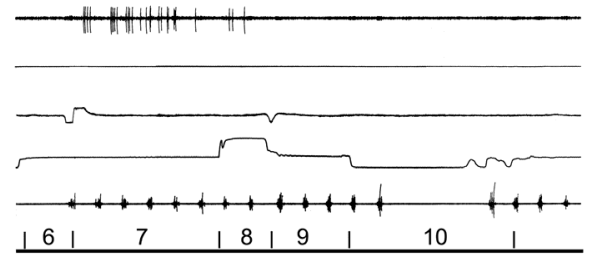

(b)

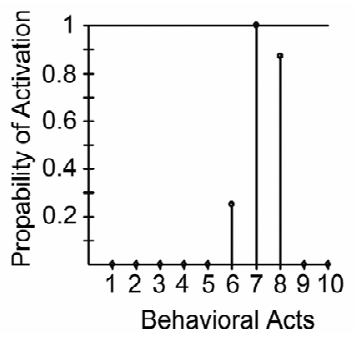

(d)

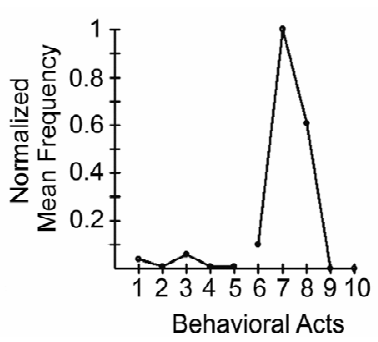

(e)

Figure 6. Example of the activity of the right-side specific SE-neuron in CA1. The cell had "specific" activation only in right side food-acquisition cycles. Details as in Figure 2. The cell was silent in left side food-acquisition cycles (a) and activated during approaching the right corner with the pedal (b). The cell was also active during approaching the right corner without the pressing the pedal (c) and during tests: forced displacement of the experimental animal in the same place by experimenter. (d, e): The probability of the presence of activation during the various behavioral acts and normalized mean frequency of activity during various behavioral acts. Note that activations of the neuron were observed in all realizations of acts 7 . The timescale is the same for $a, b$, and c; see horizontal bar ( 1 sec) under $c$.

dation procedure was used whereby each rabbit was classified by the functions derived from all samples except that particular rabbit. This procedure showed that $69 \%$ of the cross-validated grouped rabbits were correct.

The five indices are the following. Str Rad designates mainly fibers of CA1 apical dendrites of pyramidal cells. This index decreased by $6 \%$ (ns). Marked reduction of spines on CA1 pyramidal and granule cell dendrites have been shown earlier [77]. McMullen et al. [92] did not find a significant decrease in the neuronal density of CA1, but the thickness of the strata oriens and radiatum of CA1 decreased significantly after 5 months of forced alcohol treatment. V-MOL-A designates mainly upper fibers of Dg, consisting of axon collaterals of CA3 and hilar CA3 cells, granular cells dendrites, and short axon neurons. This index increased by $23 \%(\mathrm{t}=2.35$; $\mathrm{p}<$ 0.05). Similarly, Walker and Hunter found that chronic ethanol treatment reduced the spine density of CA1 pyramidal cells and increased the spine density of DG granule cells [69]. V-MOL-B designates mainly lower fibers of Dg consisting of granular cells axons, mossy fibers, polymorph cells dendrites. This index increased by $22 \%$ (ns). Hilar CA3 designates mainly a pyramidal cells layer. This index decreased by $30 \%(\mathrm{t}=2.73 ; \mathrm{p}<0.05)$. TopFd designates V-MOL-A together with granular Fd cells. This index increased by $15 \%$ (ns). Although the hilar CA3 index significantly decreased, a corresponding decrease in the size of neuronal bodies was not observed.

To understand this mismatch, we counted the number of neurons per standard square $\left(8450 \mu^{2}\right)$. This number
Table 1. Canonical discriminant function coefficients.

\begin{tabular}{cc}
\hline & Function \\
\hline Str Rad & 1 \\
V-MOL-A & -10.653 \\
V-MOL-B & 44.027 \\
hilar CA3 & 22,225 \\
TopFd & -7.769 \\
(Constant) & -33.888 \\
Unstandardized Coefficients & 2.390 \\
\hline
\end{tabular}

was $18 \%$ smaller $(\mathrm{t}=5.53 ; \mathrm{p}<0.001)$ in ethanol treated than in healthy control animals, which correlates with the hilar CA3 index decrease in the former subjects group.

\subsubsection{The Acute Effect of Ethanol on Neuronal Activity in FAB}

Our previous study showed that in healthy animals the proportion of U-units with slow background frequency decreased significantly, by $11 \%$, in E+ when compared to $\mathrm{E}-$ [42]. Corresponding a $7 \%$ decrease in ethanol treated animals was not significant.

On the contrary, in healthy rabbits, the proportion of SE neurons as a whole did not change significantly after acute ethanol administration. In ethanol treated animals, we found a tendency for the relative number of Dg SEneurons in $\mathrm{E}+$ to be larger than in $\mathrm{E}-\left(12 \%, \chi^{2}=3.80\right.$; $\mathrm{df}$ 
$=1 ; \mathrm{p}=0.051$ ). The increase in the absolute number of SE-neurons in Dg after acute administration of ethanol was significant $\left(\chi^{2}=4.42 ; \mathrm{df}=1 ; \mathrm{p}<0.05\right)$.

Changes within the group of SE neurons can also be seen after acute ethanol administration. All 8 tested CA1 place neurons that were activated in a certain place within a varying behavioral context in $\mathrm{E}+$ had their place field near the pedal, while in E- only 2 out of 6 neurons had place fields near the pedal. This difference is significant (exact Fisher criterion, $p<0.02$ ) although it is to be considered as tentative because of the very small sample size. This decrease was significant also when checking if the absolute number of CA1 pedal place cells changed from $\mathrm{E}-$ to $\mathrm{E}+$ (exact Fisher criterion, $\mathrm{p}<0.002$ ).

These changes correspond to a more general phenomenon. The relative number of hippocampal neurons that were specialized on the latest stage of learning in the experimental cage (i.e. "newest") and especially selective in respect to behavior being active during approaching and/or pressing the pedal near one wall of the experimental cage but not near the opposite wall (subgroup of SE-neurons) increased significantly after ethanol administration (from 3\% in E- to 7\% in E+; exact Fisher criterion, $\mathrm{p}<0.05$ ). On the contrary, in healthy rabbits, the relative number of these sub-group neurons decreased significantly from $7 \%$ to $1 \%$ (exact Fisher criterion, $\mathrm{p}<$ 0.02 ). Interestingly, the number of "unilateral" pedal neurons reached a control value after ethanol administration in chronic rabbits, i.e. that found in healthy animals in a sober state. Different directions of changes lead to a highly significant difference between the relative numbers of these neurons in $\mathrm{E}+$ if compared to healthy and ethanol treated animals (exact Fisher criterion, $\mathrm{p}<0.002$ ). The increase and decrease were significant also when checking the proposition about change of the absolute numbers (exact Fisher criterion, $\mathrm{p}<0.02$; in both cases).

\subsection{Experiment 2}

\section{FAB and AAB Performance}

We have previously shown that rabbits are not attracted by the substance capsules per se, they did not consume empty capsules [46]. Usually, an animal stopped AAB (i.e. refused to take capsules with ethanol from the feeder after pedal pressing) earlier than it stopped FAB. However, rabbits that had just refused to take ethanol capsules, willingly drank considerable amounts of ethanol from the syringe presented to them by an experimenter. Alcohol consumption during a recording session did not exceed $0.40 \mathrm{~g} / \mathrm{kg}$. When the duration of each behavioral act of $\mathrm{AAB}$ was compared with that of FAB, it was apparent that most acts of the former behavior (turning the head to a pedal, approaching a pedal, approaching a feeder) were significantly slower $(30 \%-46 \%)$ than that of the latter (in detail [46]).

\subsection{Neuronal Activity in FAB and AAB}

\subsubsection{Common Neurons}

73 out of 99 units recorded during behavioral cycles of both $\mathrm{AAB}$ and FAB were U-neurons. These neurons had no consistent activation during any acts of $\mathrm{AAB}$ and FAB. The majority of $U$-neurons were similarly active in $\mathrm{FAB}$ and $\mathrm{AAB}$. Our earlier data indicate that the U-neurons are related to some system of "other behaviors", not analyzed in the study $[31,42,45]$. In connection with these data, there is good reason to believe that U-neurons (representatives of "other behaviors") make a contribution (similar) to subserving both $\mathrm{AAB}$ and FAB.

However, one and the same unit might be a U-neuron in for example $\mathrm{FAB}$, but an SE-neuron in $\mathrm{AAB}$ or vice versa. Consequently, although the number of U-neurons was the same in these two behaviors $(73=73)$, the set of $\mathrm{U}$-neurons in $\mathrm{AAB}$ and $\mathrm{FAB}$ was different. The set of $\mathrm{U}$ neurons consisted of $28 \mathrm{CA} 1$ and $45 \mathrm{Dg}$ cells in FAB and of $29 \mathrm{CA} 1$ and $44 \mathrm{Dg}$ cells in AAB.

Activation of 17 neurons (10 in CA1 and 7 in Dg) were classified as NSE-neurons. All NSE-neurons demonstrated similar activity in $\mathrm{AAB}$ and $\mathrm{FAB}$, i.e. if a neuron had activation in FAB during a certain movement, e.g. turning to the right, this neuron was also activated during similar turning in AAB.

Among the neurons whose activations characteristics fitted all the criteria for the SE-neurons, there were both common as well selective neurons. One example of common neurons is shown in Figure 7. This neuron had selective "specific" activations during taking food/a capsule with ethanol from the right but not left feeder, both in FAB (7(a), (c), and (e)) and AAB (7(b), (d), and (f)). Thus, the situation was similar to that with U-neurons. The number, but not the set of SE-neurons was the same in two behaviors $(\mathrm{N}=9)$. This number consisted of 7 (5 common) CA1 SE-neurons and 2 (both common) Dg SEneurons in $\mathrm{FAB}$, while in $\mathrm{AAB}$ the distribution was the following: 6 (5 common) CA1 SE-neurons and 3 (2 common) Dg SE-neurons. Spike frequency in activations of three common SE- and NSE-neurons was significantly higher during $\mathrm{AAB}$ than $\mathrm{FAB}$; the spike frequency of one neuron was significantly lower during AAB (t-test; $\mathrm{p}<$ $0.05 \div 0.02$ )

\subsubsection{Alcohol- and Food-Selective Neurons}

Four SE-neurons had "specific" activation selectively only in $\mathrm{AAB}(\mathrm{N}=2)$ or only in FAB $(\mathrm{N}=2)$. These units were classified as specialized in relation to the acts of $\mathrm{AAB}$, i.e. as "alcohol-acquisition selective" cells or to the acts of FAB i.e. as "food-acquisition selective" cells according to the criteria given in the Methods section of 


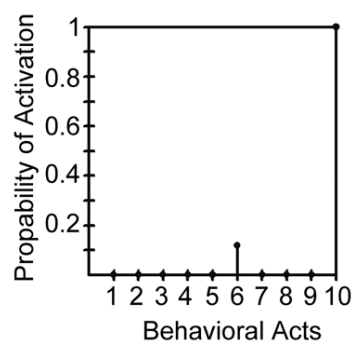

(a)

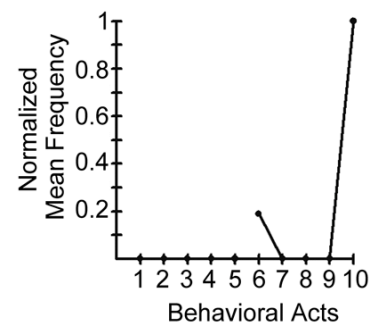

(c)

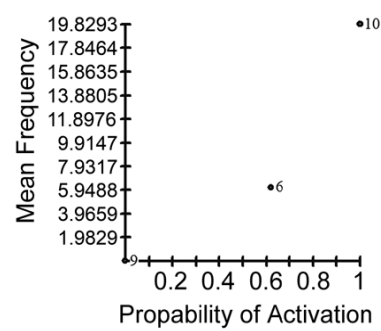

(e)

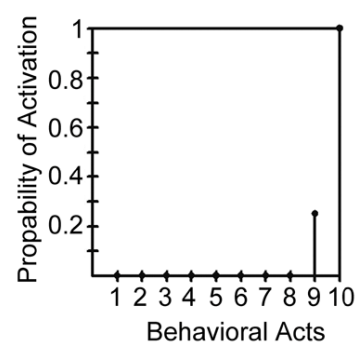

(b)

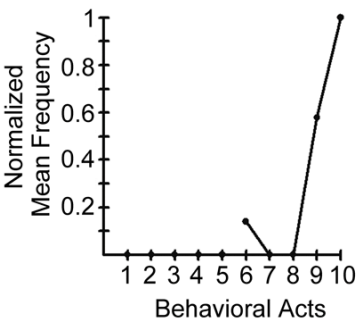

(d)

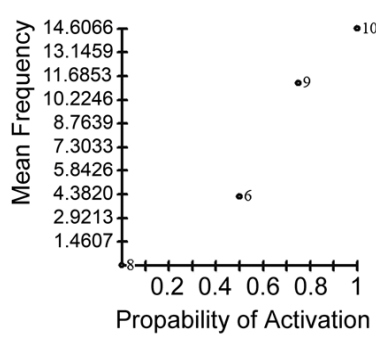

(f)
Figure 7. Example of the activity of "common" SE-neuron in CA1. The neuron had similar "specific" activations in FAB and AAB. Graphs (a-d) as in Figure 2, graphs (e and $f$ ) as in Figure 5. The neuron had "specific" activations both during taking the food (a, c, and e) and taking the capsule filed with ethanol solution (b, $d$, and f) from the right feeder (act 10). "Non-specific" activation appeared during approaching the right feeder in alcohol-acquisition behavior.

this paper. Figure 8 represents a food-selective neuron whose "specific" activations appeared only in FAB. In $\mathrm{AAB}$, the neuron demonstrated only "non-specific" activations. Figure 9 represents an alcohol-selective neuron. It has "specific" activation during approaching the left pedal in AAB. Tests showed that it has a place field near this pedal. This field manifests itself only in AAB.

\section{Discussion}

\subsection{The Effect of Chronic Ethanol Treatment on Hippocampus Neurons}

Our data shows that the pattern of neuronal behavioral specializations in hippocampus changes after chronic ethanol treatment. Significant changes (increase) were observed only in the proportion of U-neurons, but not in $\mathrm{SE}$ and NSE-neurons. In the cingulate cortex, the proportions of all neurons changed [45]. In the motor cortex,

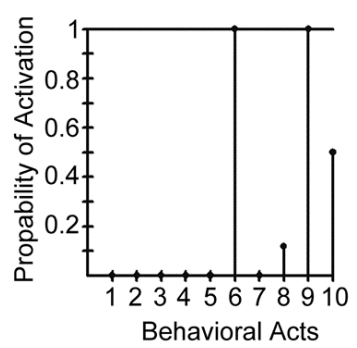

(a)

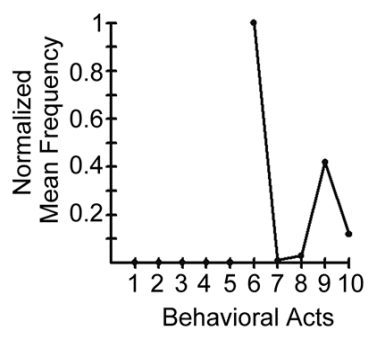

(c)

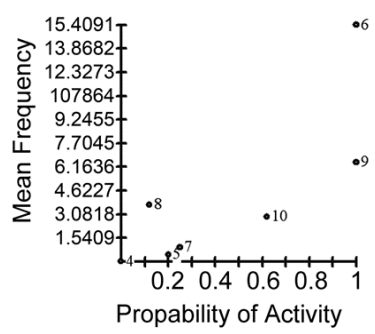

(e)

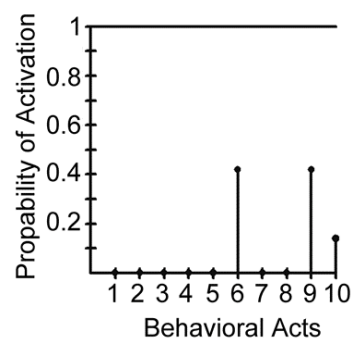

(b)

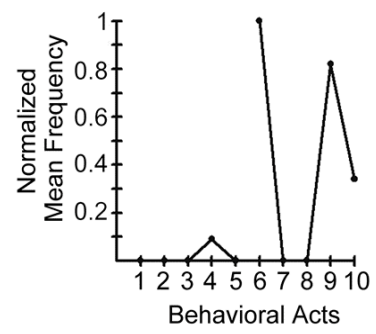

(d)

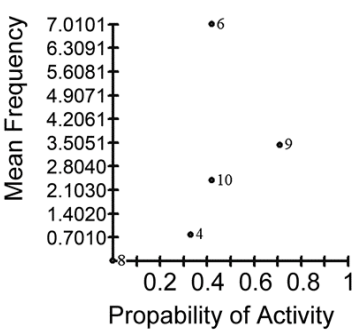

(f)
Figure 8. Example of the activity of food specific SE-neuron in CA1. The neuron had "specific" activation only in the FAB (a, c, and e). "Non-specific" activation appeared in the "same" acts during AAB (b, d, and f). Details as in Figure 7.

the proportions of different neuron types did not change [47]. As a whole, our results show that the strength of ethanol influence is strongest in the cingulate cortex, somewhat weaker in the hippocampus, and weakest in the motor cortex. In this respect, the acute and chronic effects of ethanol are similar.

The number of SE-neurons was similar in chronic and healthy animals. However, the number of neurons belonging to the "pedal" subgroup of SE-neurons decreased significantly both after chronic ethanol treatment and acute ethanol administration in healthy animals. These neurons belong to the newest systems formed at the latest stage of learning that starts from taking food from a feeder and proceeds through the development of the approach to a pedal and comes to an end with training to press the pedal.

Our results are in line with the Ribot-Jackson principle, stating that those mechanisms which appear last are most prone to disintegration [93]. However, a difference in direction of changes was also observed. For example, the number of U-neurons was larger in chronically-treated than in healthy animals, but in healthy animals ethanol 


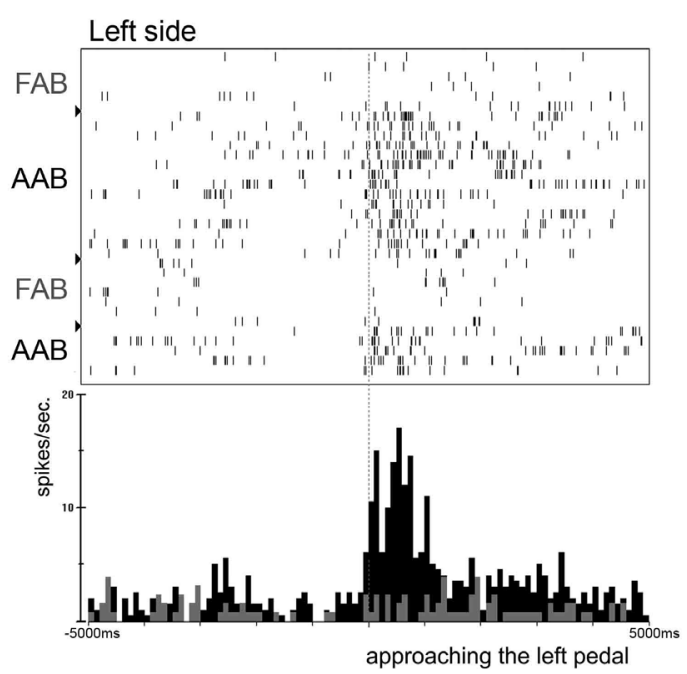

(a)

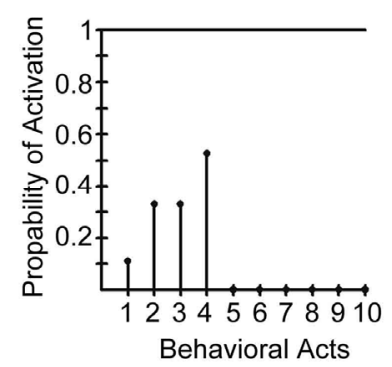

(c)

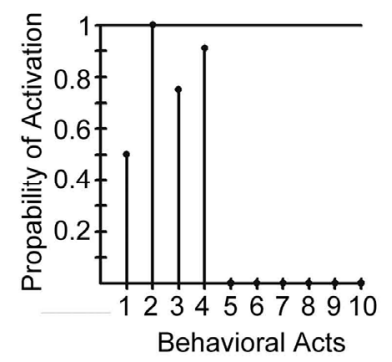

(f)

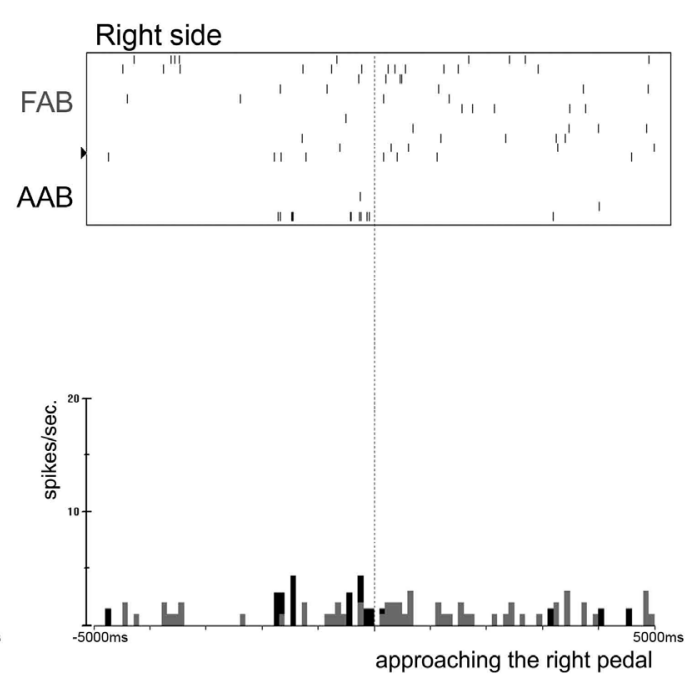

(b)

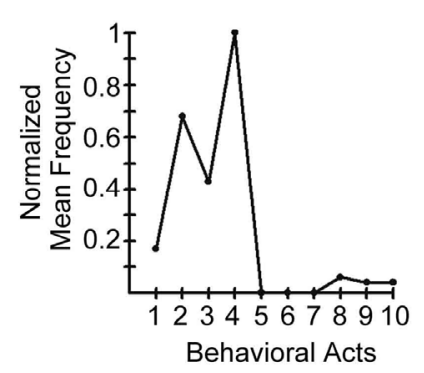

(d)

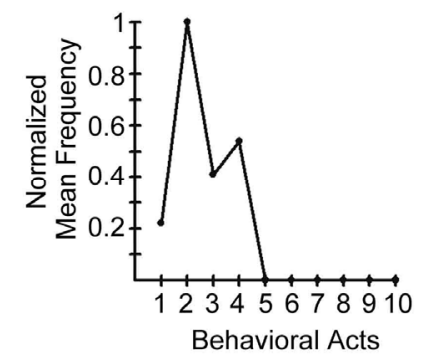

(g)

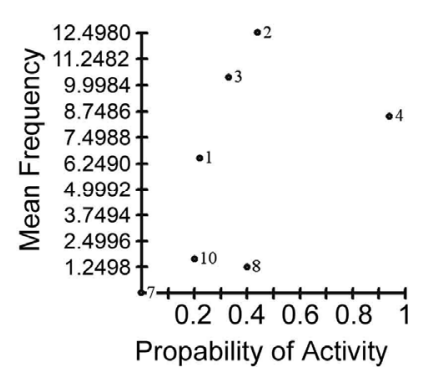

(e)

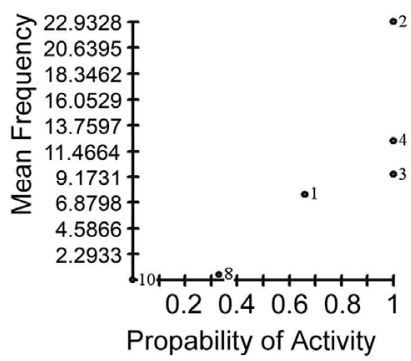

(h)

Figure 9. Example of the activity of alcohol specific SE-neuron in CA1. The neuron had "specific" activation only in the AAB. The neuron activated "specifically" during approaching the left pedal in AAB (f-h) but not FAB (c-e). UP: Raster plots and histograms are constructed in relation to the start of approaching the pedal in the left side cycle (a, act 2) and right side cycle (b, act 7). Vertical bars on raster plots correspond to spike of single neuron and horizontal bars show sequences of spikes in an individual cycle of FAB or AAB behaviors. Cumulative histograms with the bin width of 100 ms are shown beneath the raster plots. Gray histograms for FAB, black histograms for AAB; (c-h) as in Figure 7.

decreased the number of U-neurons.

Hippocampal morphology is very sensitive to chronic ethanol $[68,94,95]$. There is evidence that the main target of ethanol is the NMDA-receptor system [68,96], which may be influenced indirectly via GABAAR neurotransmission [97]. In rodents, the extent of hippocampal neuronal loss ranges from $10 \%$ to $40 \%$ (for a review, see [68]), in our data it was $18 \%$.

High neuronal loss and a reduction of the total hippocampus volume has been found also in people who drink heavily [91,98]. Cadete-Leite et al. [99] (p. 12) concluded that chronic ethanol treatment leads to Dg cells loss, along with dendritic regrowth compensating for the loss of granule cells. We assume that changes in the thickness of different hippocampus layers found in the present experiments may be due to the following factors: the loss of pyramidal cells, interneurons (which are present in all layers), metabolic modifications in the cells' bodies and/ or their axons and dendrites, a compensatory increase in length, as well as branching of dendrites, and their addi- 
tional myelinisation.

Similar to King et al. [94], we found an opposite direction of changes in indexes that readily differentiate healthy from chronic animals. Fibers of CA1 (apical dendrites of pyramidal cells) decreased, and Dg granular cells dendrites increased. Re-growing of the dendrites of granule cells was reported also by Paula-Barbosa et al. [95]. Comparative analysis of the degree of chronic ethanol influence on the pattern of specializations in CA1 and Dg shows that the former is more sensitive to the influence mentioned. The results of the pattern analysis agrees well with our another data set [24], showing that the c-fos (immediate-early gene) expression resulting from a behavioral mismatch (that is the first stage of learning; $[19,34,61])$ is stronger in CA1 than in Dg. However, based on histological criteria, it seems that Dg has been modified more, and this modification includes re-growing. The criterion used is important here. Using another criterion, decrease of rate of local cerebral glucose utilization, led Smith et al. [100] to conclude that CA1 and DG are equally susceptible to chronic ethanol treatment. Bengoechea and Gonzalo [101] demonstrated that after 70 days of ethanol intake, neuron loss was significantly more prominent in hilar CA3 than in CA1. Similarly, Miki et al. [11] showed that according to this criterion the hilus region is particularly vulnerable to the chronic ethanol effects, also during early postnatal life in rats. Probably, this dissimilarity reflects different dynamics and/ or content of adaptation processes deploying in the structures owing to toxic ethanol influences. Alternatively, smaller sensitivity of Dg activity to alcohol might be, at least partly, due to more expressed morphological modifications in this structure.

Neurogenesis may also contribute to the maintaining of the optimal functioning of $\mathrm{Dg}$ [102-104]. It might be a mechanism of hippocampal rearrangement after chronic ethanol administration [105]. Neuron precursor cells in adults proliferate at the border of the dentate granule cell layer and the hilus; BrdU-labeled cells (that may co-express neuronal markers) can be detected in both sub-regions of humans and animals [103,106,107]. Gould et al. [108] have shown that the number of adult-generated neurons doubles in Dg due to learning. Although short-duration ethanol self-administration (less than 2 weeks) decreases neurogenesis in Dg, exercise stops this decrease [109]. In the present experiment, exercise is FAB realization and AAB learning and realization. Moreover, Åberg et al. [105] have found that long-term (about 10 weeks) moderate ethanol consumption leads to an increase of neurogenesis in Dg, both in its rostral and caudal parts. They stress that a key factor in their experiments was that animals had free access to water and ethanol, and were able, as in our experiments, to regulate ethanol intake at will. Forced ethanol administration decreases neurogene- sis in hippocampus. Forced administration of large ethanol doses causes also an opposite effect, so that most sever morphological alterations were in CA1 [110]. Åberg et al. [105] (pp. 1, 9) assume that new cells in the Dg may subserve the long-lasting modifications of brain function after ethanol treatment, including a role in learning and memory. Nilsson et al. [106] also make note of the clear relation between enhanced neurogenesis in adult hippocampus with improved memory.

\subsection{The Effect of Acute Ethanol Treatment on the Involvement of Hippocampal Neurons in Subserving of Instrumental FAB}

Acute ethanol increases the duration of FAB cycles in healthy animals [31]. Interestingly, acute ethanol decreased the duration of FAB in ethanol treated animals. However, the number of mistakes in behavior (e.g., missing a pedal, checking feeders without pressing a pedal) increased significantly [45].

As in the cingulate cortex [45], we observed an opposite effect of acute ethanol administration on the activity of SE-neurons in chronic and healthy animals. In chronic animals, their proportion increased, and in healthy ones it decreased. Acute ethanol in chronic animals increased the number of hippocampal "pedal" neurones, while this number decreased in healthy ones. Importantly, in chronic animals, acute administration of ethanol increased the number of "unilateral" "pedal neurons". In sober state, their number was smaller in chronic than in healthy animals. Thus, acute ethanol shifted their proportion towards the normal value.

Acute alcohol satisfies the alcohol need, and establishes the temporal balance in the catecholamine turnover $[111,112]$ and results, as is evident from the present and our earlier data [45], in the involvement of additional SE-neurons in the subserving of behavior. In the analysis of cingulate cortex data, we used a log-linear analysis to discover the source of additional SE-neurons. We found evidence that additional SE-neurons were recruited from the pool of U-neurons, and evidence of those SE-neurons that were silent in $\mathrm{E}^{-}$. However, in the hippocampus, acute ethanol did not decrease the number of U-neurons significantly. If a need for alcohol, at least partly, inhibits other behaviors in alcoholics [113], reduction in need might lead to disinhibition of previously silent food-acquisition SE-neurons, and their involvement in FAB. In any case, the increase in the number of SE-neurons leads to a transient and partial normalization of the pattern of behavioral specializations in ethanol treated rabbits. Similarly, neurons in the primary somatosensory cortex of ethanol treated rats have normalized (but are not quite normal) responses to sensory stimulation after acute ethanol treatment [79]. 
Our data agree with previous ones showing that acute ethanol administration has a normalizing effect upon the test performance of alcoholics [114,115]. A small amount of alcohol has been shown to improve the creative output of writers, artists, and composers who drink heavily [116]. Our results suggest that such an improvement might be partly caused by transient normalization of the pattern of neuronal behavioral specializations in alcohol-sensitive neurons in the cingulate cortex and hippocampus.

\subsection{Involvement of the Hippocampus in the Formation of New and Modification of Existing Behavior}

Despite the relatively small quantity of ethanol consumed by the animals during the experiment involving recording of neuron activity lasting eight hours or more, none of the animals showed any signs of physical withdrawal. Such signs are rarely seen in animals taking ethanol in conditions of free choice and are not an obligatory component for determining their dependence.

Comparison of neuron activity in FAB and AAB showed that sets of neurons involved in both behaviors overlapped strongly, the majority of neurons being common to these behaviors. As we noted in our Introduction, the irregular spiking of U-neurons might reflect their participation in behavior that we are not aware of. The present data, showing that a unit giving "specific" activation in one behavior may be a U-neuron in another behavior, are in line with this suggestion. Therefore, both common neurons and U-neurons of undefined specialization might be involved in FAB and AAB.

Our previous results suggest that the basis of learning a new behavior is the establishment of permanent specializations of previously "silent" neurons, which become active and start to take a role in subserving newly formed behavior $[33,35,36,48]$. Others have shown that 1) the newly formed neuron specializations and morphological changes seem to be permanent, 2) recruitment of "silent" neurons into the subserving of behavior could be an important learning mechanism [117] (p. 813) and 3) there are many silent neurons in different brain areas $[50,59$, 118-132]. These findings support the suggestion that new neurons become involved rather than the specialization of previously specialized neurons changing. New neurons appearing in adult neurogenesis are also likely to be involved in the process of the formation of new behaviors (e.g. [34,133-136]).

In the present experiment, the formation of premorbid FAB is the stage of individual development preceding the formation of AAB. The existence of common neurons involved in both types of behavior supports the view that the neuronal mechanisms of pre-existing (in this case premorbid) behavior provide the basis for the formation of the neuronal mechanisms of new behavior directed at satisfying the new need that of alcohol. Common neurons might be ones specialized in relation to systems of previously formed behavior which do not lose their specialization, but undergo modifications associated with the fact that the systems in relation to which they were specialized are involved in performing the newly formed behavior. We regard this type of modification occurring after new learning, and concerning cells belonging to systems formed before the learning, as processes of reconsolidation (see e.g. [137]) and called it "accommodative" reconsolidation $[35,46,48]$. Such modifications might explain the quantitative differences in the activity of common SE- and NSE-neurons in FAB compared to AAB observed here.

The initial stage of consolidatory and reconsolidatory changes associated with the formation of neuronal specialization for newly formed systems is probably the expression of early genes that may be considered as a molecular indicator of a mismatch between the need to achieve a goal and the absence in individual memory of the appropriate way to achieve it [22-24,34,36,61]. Early genes are expressed in association with accommodative reconsolidation of the type which NSE-neurons undergo during the formation of AAB [138]. Castro-Alamancos et al. [139] showed that the training of rats to press a pedal with the paw was associated with significant increases in the level of early gene expression in the projection zone of the motor cortex. We think that our new data agrees with this suggestion, taking into account that most changes in the motor cortex (at least in rats and rabbits) during training are not due to formation of new specializations, but are modifications of previously formed systems, associated with the reorganization of pre-existing structures of individual experience during learning [39,48,49].

The sets of neurons associated with FAB and AAB are not identical. We found a small proportion of food-selective and alcohol-selective neurons showing specific activation only in FAB or only in AAB correspondingly. There is evidence that the neuronal mechanisms of juiceacquiring and cocaine-acquiring behaviors in monkeys and rats are also partially separated ([140] (p. 1072) and [141]).

We have previously identified alcohol-selective SEneurons in the posterior cingulate [46] and in the motor [48] cortex. Assuming that the formation of specialization of new neurons underlies learning, we believe that alcohol-selective neurons are specialized during the formation of AAB. We have not found food-selective cells in the above structures. Nevertheless, on the basis of data showing such neurons in other experimental situations (differentiation of food from non-food objects or food from water and salt, see [37,142]) we have suggested that it is extremely difficult to prove the non-existence of the 
food-selective SE neurons [46] (p. 95). It is perhaps more proper to say that the occurrence of alcohol-selective cells in our experimental conditions was significantly higher. Indeed, the present results show the existence of such neurons in the hippocampus. Probably food-selective cells were "added" to the FAB-group cells during AAB formation as a component of accommodative reconsolidation processes.

We found a small number of behaviorally selective neurons in our experiment. Robinson and Carelli [143], who recently compared activity of nucleus accumbens neurons in instrumental (pedal pressing) $\mathrm{AAB}$ and in water-acquisition behavior found that only $15 \%$ of the neurons are common to both behaviors. There are several reasons that can explain the discrepancy of the results, such as the experimental animals, the studied brain structure, the reinforcement type, the classification of neurons, and the history of learning. An important difference is that in our experiments, pressing one and the same pedal provided food or alcohol, but in the study by Robinson and Carelli there were separate pedals for water and ethanol.

Differences in neuronal organization of FAB and $A A B$ can be examined from the point of place neurons concept. Our previous and present data indicate that the activation of place units corresponded to the space which was divided into "fields" in relation to the behavioral acts the animal realized while approaching the goal-objects in the given environment $[36,42,46,60]$. Also other studies support this view [57,58,90,144-152]. Accordingly, all SEneurons may be considered as place units, which are active in a given place (or places), because this place was related to the appropriate results of the behavior. The difference between those SE-neurons which were in our study classified as classic place units, and the other type of SE-neurons would then be that the latter belong to systems involved only in instrumental behaviors, but the classic place units are also active in many other acts realized in the same location.

If SE-neurons are place neurons, this means that the involvement of new alcohol-selective SE-neurons in the subserving of behavior during learning of the $\mathrm{AAB}$ is "re-division" "“relocation" according to [146,147]; this is "remapping" according to [153]) of the experimental cage because of the appearance new place cells, although the location of goal-objects in the cage stays invariable. The occurrence of place-related activation of a given neuron at a given place in a cage in one behavior, and the absence of such activation of the same neuron in another behavior deploying in the same cage without changing any environmental cues (Figure 9; see also [149,151,153, 154]) supports the idea of re-division. This is in line with the earlier idea by Markus et al. that place fields emerge due to learning [149] (p. 7093). Thus, in our experiments, re-division implies that physically the same environment is presented by different hippocampal activity before and after $\mathrm{AAB}$ formation.

On the basis of the chronic effect of alcohol, we can suggest at least two mutually related aspects of neuronal modifications determining the similarity between the neuronal mechanisms underlying the formation of longterm memory and long-lived adaptation arising during chronic exposure to alcohol (c.f. the introduction to this paper).

First is the loss of synapses and death of some cells with simultaneous hyperinnervation of others, due to the toxic action of ethanol [94] that probably takes place in our experiments. This may be considered as a morphological description of reorganizations that manifest itself functionally in the change of the FAB's pattern of neuronal specializations in ethanol treated vs healthy animals. Long-lasting expression of FOS family proteins is induced by drugs administration [155] and prolonged activation of immediate genes (c-fos, c-jun) relates to delayed neuronal death in the hippocampus [156]. There is experimental evidence suggesting that death of neurons may be a component of processes of memory formation as well [157]. Changes in the numbers of synapses are also known to be an important component of the structural rearrangements accompanying the formation of long term memory $[128,130,158]$.

Secondly, a particular type of long-lived adaptation, which occurs in chronic alcohol consumption, is indeed very similar to the modifications underlying the formation of new memory. These include rearrangements of neurons associated with the formation of new specializations for $\mathrm{AAB}$ and with processes of accommodative reconsolidation of premorbid specializations. The problem is the relation between newly formed $\mathrm{AAB}$ and different kinds of premorbid behaviors: AAB strongly inhibit neurons of these pre-exiting behaviors that can be realized only if the AAB goal is satisfied, i.e. after consumption of alcohol. Thus our data agree with the suggestion that drug addiction is an unusual form of learning [18] (p. 569).

Kelley [19] has shown that exposure of rats to "drugpaired" conditions induces c-fos expression (in turn evoked by NMDA activation) reflecting a mismatch between wanting the drug and its absence. It is the beginning of new learning directed to the establishment of addictive behavior. According to Kelley [19], addiction is basically new learning and addictive drugs use the same neuronal mechanisms as are used in reinforcement learning. Our thinking is very similar, suggesting that similar mechanisms of neural specialization underlie both "normal" and "addictive" learning.

A major clinical challenge for the treatment of drug addiction is its perseverance even after long-lasting drug 
abstinence [159]. Nestler and Aghajanian [17] specifically asked why alcoholism recurs even after many years of abstinence. We suggest that this is because newly formed neuronal specializations during abstinence do not replace previously formed specializations for alcohol consumption, but, rather supplement them. Chandler and Kalivas [20] state that drug acquisition behavior becomes "hard-wired" in the brain and may be repeatedly and easily reactivated. Persistence of neuronal alcohol specific specializations can be considered as a factor in the hardwiring. As "mechanisms mediating neuroadaptations induced by chronic drug exposure and their behavioral consequences (addiction) may be similar in different species", it is not strange that relapse is "highly predictive ... after withdrawal" not only in humans but also in animals [160] (pp. 1016, 1014). Gene expression (starting with immediate gene activation) underlying the formation of new neuronal specializations plays the key role in these mechanisms, underlying behavioral adaptations in normal and in pathological states. The recent review by Robison and Nestler [155] presents strong arguments that alterations in gene activity considerably contribute to the addictive phenotype. $\triangle$ FOSB is encoded by the FosB gene and belongs to FOS family transcription factors. Expression of $\triangle$ FOSB may be induced by many drugs and is linked to various addiction-related behaviors.

\section{Conclusions}

Here we show that chronic ethanol treatment modifies the activity and morphology of rabbit hippocampus neurons. Our results indicate that the strength of chronic ethanol influence, as also the effect of acute ethanol in healthy animals, is strongest in the cingulate cortex, somewhat weaker in the hippocampus, and weakest in the motor cortex. Thus, the acute effects of alcohol are predictive for its chronic effects. We suggest that the subserving of behavior by hippocampus changes because of ethanol causes adaptive reorganization of neurons, as well as because of formation of new neuronal specializations in relation to the behavior directed at getting alcohol, and, in relation to this, because of modification of functioning of neurons belonging to earlier formed behaviors. Our new results help us to understand how closely the neuronal mechanisms in the hippocampus underlying newly formed and previously formed behaviors are connected through neurons common for both behaviors. The results also demonstrate the similarity of the neuronal mechanisms of long-term memory and long-lived modifications of the nervous system occurring in conditions of repeated dosage with alcohol and probably with other addictive substances.

This work was supported by The Grant of the Council of the President of the Russian Federation for Leading
Scientific Schools (\#3010.2012.6).

\section{Author Contributions}

Designed the experiments: Y. I. Alexandrov, Y. V. Grinchenko. Performed the experiments: Y. I. Alexandrov, Y. V. Grinchenko, S. Laukka, V. N. Mats. Analyzed the data: Y. I. Alexandrov, R. G. Averkin, Y. V. Grinchenko, D. G. Shevchenko, M. Sams. Wrote the paper: Y. I. Alexandrov, R. G. Averkin, M. Sams.

\section{REFERENCES}

[1] P. Somogyi, "Hippocampus: Intrinsic Organization," In: P. Shepherd and S. Grillner, Eds., Handbook of Brain Microcircuits, Oxford University Press, New York, 2010, pp. 148-164.

[2] O. S. Vinogradova, "Functional Organization of the Limbic System in the Process of Registration of Information: Facts and Hypotheses," In: R. L. Isaakson and K. H. Pribram, Eds., The Hippocampus, Plenum Press, New York, 1984, pp. 1-69.

[3] L. R. Squire, "Memory and the Hippocampus: A Synthesis from Findings with Rats, Monkeys, and Humans," Psychological Review, Vol. 99, No. 2, 1992, pp. 195-231. doi:10.1037/0033-295X.99.2.195

[4] H. Eichenbaum "The Hippocampal System and Declarative Memory in Animals," Journal of Cognitive Neuroscience, Vol. 4, No. 3, 1992, pp. 217-231. doi:10.1162/jocn.1992.4.3.217

[5] G. Buzsaki, "The Hippocampo-Neocortical Dialogue," Cereb Cortex, Vol. 6, No. 2, 1996, pp. 81-92. doi:10.1093/cercor/6.2.81

[6] D. B. Matthews and A. L. Morrow, "Effects of Acute and Chronic Ethanol Exposure on Spatial Cognitive Processing and Hippocampal Function in the Rat," Hippocampus, Vol. 10, No. 1, 2000, pp. 122-130.

doi:10.1002/(SICI)1098-1063(2000)10:1<122::AID-HIP O13>3.0.CO;2-V

[7] J. M. Silvers, S. Tokunaga, R. B. Berry, A. M. White and D. B. Matthews, "Impairments in Spatial Learning and Memory: Ethanol, Allopregnanolone, and the Hippocampus," Brain Research Reviews, Vol. 43, No. 3, 2003, pp. 275-284. doi:10.1016/j.brainresrev.2003.09.002

[8] E. T. Rolls, "A Computational Theory of Episodic Memory Formation in the Hippocampus," Behavioural Brain Research, Vol. 215, No. 2, 2010, pp. 180-196. doi:10.1016/j.bbr.2010.03.027

[9] M. F. Carr, S. P. Jadhav and L. M. Frank, "Hippocampal Replay in the Awake State: A Potential Substrate for Memory Consolidation and Retrieval," Nature Neuroscience, Vol. 14, No. 2, 2011, pp. 147-153. doi:10.1038/nn.2732

[10] A. M. White and P. J. Best, "Effects of Ethanol on Hippocampal Place-Cell and Interneuron Activity," Brain Research, Vol. 876, No. 1-2, 2000, pp. 154-165. doi:10.1016/S0006-8993(00)02629-9

[11] T. Miki, S. J. Harris, P. Wilce, Y. Takeuchi and K. S. Bedi, "Neurons in the Hilus Region of the Rat Hippo- 
campus Are Depleted in Number by Exposure to Alcohol During Early Postnatal Life," Hippocampus, Vol. 10, No. 3, 2000, pp. 284-295. doi:10.1002/1098-1063(2000)10:3<284::AID-HIPO9>3.0 .CO;2-K

[12] B. Givens, J. M. Williams and T. M. Gill, "Septohippocampal Pathway as a Site for the Memory-Impairing Effects of Ethanol," Hippocampus, Vol. 10, No. 1, 2000, pp. 111-121. doi:10.1002/(SICI)1098-1063(2000)10:1<111::AID-HIP O12>3.0.CO;2-1

[13] S. Kumar, P. Porcu, D. F. Werner, D. B. Matthews, J. L. Diaz-Granados, R. S. Helfand and A. L. Morrow, "The Role of GABA(A) Receptors in the Acute and Chronic Effects of Ethanol: A Decade of Progress," Psychopharmacology, Vol. 205, No. 4, 2009, pp. 529-564. doi:10.1007/s00213-009-1562-Z

[14] T. Tsurugizawa, A. Uematsu, H. Uneyama and K. Torii, "The Role of the Gabaergic and Dopaminergic Systems in the Brain Response to an Intragastric Load of Alcohol in Conscious Rats," Neuroscience, Vol. 171, No. 2, 2010, pp. 451-460. doi:10.1016/j.neuroscience.2010.09.016

[15] L. M. Garcia-Moreno, N. M. Conejo, A. Capilla, O. Garcia-Sanchez, K. Senderek and J. L. Arias, "Chronic Ethanol Intake and Object Recognition in Young and Adult Rats," Progress in Neuro-Psychopharmacology \& Biological Psychiatry, Vol. 26, No. 5, 2002, pp. 831-837. doi:10.1016/S0278-5846(01)00327-X

[16] D. B. Matthews and J. R. Silvers, "The Use of Acute Ethanol Administration as a Tool to Investigate Multiple Memory Systems," Neurobiology of Learning and Memory, Vol. 82, No. 3, 2004, pp. 299-308. doi:10.1016/j.nlm.2004.06.007

[17] E. J. Nestler and G. K. Aghajanian, "Molecular and Cellular Basis of Addiction," Science, Vol. 278, No. 5335, 1997, pp. 58-63. doi:10.1126/science.278.5335.58

[18] T. W. Robbins and B. J. Everitt, "Drug Addiction: Bad Habits Add up," Nature, Vol. 398, No. 6728, 1999, pp. 567-570. doi: $10.1038 / 19208$

[19] A. E. Kelley, "Memory and Addiction: Shared Neural Circuitry and Molecular Mechanisms," Neuron, Vol. 44, No. 1, 2004, pp. 161-179. doi:10.1016/j.neuron.2004.09.016

[20] L. J. Chandler and P. W. Kalivas, "Neuroscience: Brain's Defence against Cocaine," Nature, Vol. 455, No. 7214, 2008, pp. 743-744. doi:10.1038/455743a

[21] B. Milner, L. R. Squire and E. R. Kandel, "Cognitive Neuroscience and the Study of Memory," Neuron, Vol. 20, No. 3, 1998, pp. 445-468. doi:10.1016/S0896-6273(00)80987-3

[22] K. V. Anokhin, "Memory Consolidation: Narrowing the Gap between Systems and Molecular Genetic Neurosciences," In: R. Miller, A. M. Ivanitsky and P. M. Balaban, Eds., Conceptual Advances in Brain Research, Complex Brain Functions Conceptual Advances in Russian Neuroscience, Harwood Academic Publishers, Amsterdam, 2000, pp. 53-72.

[23] O. E. Svarnik, Y. I. Alexandrov, V. V. Gavrilov, Y. V. Grinchenko and K. V. Anokhin, "Fos Expression and
Task-Related Neuronal Activity in Rat Cerebral Cortex after Instrumental Learning," Neuroscience, Vol. 136, No. 1, 2005, 33-42. doi:10.1016/j.neuroscience.2005.07.038

[24] O. E. Svarnik and Y. I. Alexandrov, "Differential c-Fos Activation in CA1, CA3 and Dentate Gyrus Areas of Hippocampus after Various Phases of Appetitive Instrumental Learning," International Symposium "Hippocampus and Memory" Abstracts, Pushchino, 2006, p. 110.

[25] W. R. Klemm, C. G. Mallari, L. R. Dreyfus, J. C. Fiske, E. Forney and J. A. Mikeska, "Ethanol-Induced Regional and Dose-Response Differences in Multiple-Unit Activity in Rabbits," Psychopharmacology, Vol. 49, No. 3, 1976, pp. 235-244. doi:10.1007/BF00426822

[26] S. F. Zornetzer, D. W. Walker and B. E. Hunter, "Neurophysiological Changes Produced by Alcohol," In: Biomedical Processes and Consequences of Alcohol Use, Government Printing Office, Washington DC, 1982, pp. 95-128.

[27] A. M. White, D. B. Matthews and P. J. Best, "Ethanol, Memory, and Hippocampal Function: A Review of Recent Findings," Hippocampus, Vol. 10, No. 1, 2000, pp. 88-93.

doi:10.1002/(SICI)1098-1063(2000)10:1<88::AID-HIPO 10>3.0.CO;2-L

[28] N. D. Volkow, Y. Ma, W. Zhu, J. S. Fowler, J. Li, M. Rao, K. Mueller, K. Pradhan, C. Wong and G. J. Wang, "Moderate Doses of Alcohol Disrupt the Functional Organization of the Human Brain," Psychiatry Research, Vol. 162, No. 3, 2008, pp. 205-213.

doi:10.1016/j.pscychresns.2007.04.010

[29] H. Morikawa and R. A. Morrisett, "Ethanol Action on Dopaminergic Neurons in the Ventral Tegmental Area: Interaction with Intrinsic Ion Channels and Neurotransmitter Inputs," International Review of Neurobiology, Vol. 91, 2010, pp. 235-288. doi:10.1016/S0074-7742(10)91008-8

[30] C. P. Blomeley, S. Cains, R. Smith and E. Bracci, "Ethanol Affects Striatal Interneurons Directly and Projection Neurons through a Reduction in Cholinergic Tone," Neuropsychopharmacology, Vol. 36, No. 5, 2011, pp. $1033-$ 1046. doi:10.1038/npp.2010.241

[31] Y. I. Alexandrov, Y. V. Grinchenko, S. Laukka, T. Jarvilehto, V. N. Maz and I. A. Svetlajev, "Acute Effect of Ethanol on the Pattern of Behavioural Specialization of Neurons in the Limbic Cortex of the Freely Moving Rabbit," Acta Physiologica Scandinavica, Vol. 140, No. 2, 1990 , pp. $257-268$. doi:10.1111/j.1748-1716.1990.tb08997.x

[32] P. K. Anokhin, "Biology and Neurophysiology of Conditioned Reflex and Its Role in Adaptive Behavior," Pergamon Press, Oxford, 1973.

[33] V. B. Shvyrkov, "Behavioral Specialization of Neurons and the System-Selection Hypothesis of Learning," In: F. Klix and H. Hagendorf, Eds., Human Memory and Cognitive Capabilities, Elsevier, Amsterdam, 1986, pp. 599611.

[34] Y. I. Alexandrov, "Learning and Memory: Traditional and Systems Approaches," Neuroscience and Behavioral Physiology, Vol. 36, No. 9, 2006, pp. 969-985. 


\section{doi:10.1007/s11055-006-0133-6}

[35] Y. I. Alexandrov, "How We Fragment the World: The View from Inside versus the View from Outside," Social Science Information, Vol. 47, No. 3, 2008, pp. 419-457. doi:10.1177/0539018408092580

[36] Y. I. Alexandrov, T. N. Grechenko, V. V. Gavrilov, A. G. Gorkin, D. G. Shevchenko, V. Grinchenko Yu, I. O. Aleksandrov, N. E. Maksimova, B. N. Bezdenezhnych and M. V. Bodunov, "Formation and Realization of Individual Experience," Neuroscience and Behavioral Physiology, Vol. 27, No. 4, 2000, pp. 441-454. doi:10.1007/BF02462946

[37] Y. I. Alexandrov and A. V. Korpusova, "Role of Goal in Determination of Neuronal Activity of the Rabbit Motor and Visual Cortical Areas," Neuroscience and Behavioral Physiology, Vol. 17, No. 6, 1987, pp. 473-479. doi:10.1007/BF01186344

[38] Y. I. Alexandrov, Y. V. Grinchenko, I. A. Svetlaev and O. Abdrashitov, "Factors Determining the Effect of Acute Ethanol Administration on Behavior Realization," I.P. Pavlov Journal of Higher Nervous Activity, Vol. 39, 1989, pp. 1149-1151. (In Russian)

[39] Y. I. Alexandrov, Y. V. Grinchenko and T. Jarvilehto, "Change in the Pattern of Behavioural Specialization of Neurons in the Motor Cortex of the Rabbit Following Lesion of the Visual Cortex," Acta Physiologica Scandinavica, Vol. 139, No. 1-2, 1990, pp. 371-385. doi:10.1111/j.1748-1716.1990.tb08936.X

[40] Y. I. Alexandrov, Y. V. Grinchenko, S. Laukka, T. Jarvilehto and V. N. Maz, "Acute Effects of Alcohol on Unit Activity in the Motor Cortex of Freely Moving Rabbits: Comparison with the Limbic Cortex," Acta Physiologica Scandinavica, Vol. 142, No. 3, 1991, pp. 429-435. doi:10.1111/j.1748-1716.1991.tb09177.x

[41] L. I. Alexandrov and Y. I. Alexandrov, "Changes of Auditory-Evoked Potentials in Response to Behaviorally Meaningful Tones Induced by Acute Ethanol Intake in Altricial Nestlings at the Stage of Formation of Natural Behavior," Alcohol, Vol. 10, No. 3, 1993, pp. 213-217. doi:10.1016/0741-8329(93)90038-P

[42] Y. I. Alexandrov, Y. V. Grinchenko, S. Laukka, T. Jarvilehto, V. N. Maz and A. V. Korpusova, "Effect of Ethanol on Hippocampal Neurons Depends on Their Behavioural Specialization," Acta Physiologica Scandinavica, Vol. 149, No. 1, 1993, pp. 105-115. doi:10.1111/j.1748-1716.1993.tb09598.x

[43] Y. I. Alexandrov, A. V. Korpusova, Y. V. Grinchenko, V. N. Mats, S. Laukka and T. Jarvilehto, "Structural Changes and Reorganization of the Activity of the Cortical Neurons in the Behavior of Chronically Alcoholized Rabbits," I.P. Pavlov Journal of Higher Nervous Activity, Vol. 44, 1994, pp. 1077-1085. (In Russian)

[44] Y. Alexandrov, M. Sams, J. Lavikainen, K. Reinikainen and R. Naatanen, "Differential Effects of Alcohol on the Cortical Processing of Foreign and Native Language," International Journal of Psychophysiology, Vol. 28, 1998, pp. 1-10. doi:10.1016/S0167-8760(97)00066-4

[45] Y. I. Alexandrov, Y. V. Grinchenko, M. V. Bodunov, V. N. Matz, A. V. Korpusova, S. Laukka and M. Sams,
"Neuronal Subserving of Behavior before and after Chronic Ethanol Treatment," Alcohol, Vol. 22, No. 2, 2000, pp. 97-106. doi:10.1016/S0741-8329(00)00111-7

[46] Y. I. Alexandrov, Y. V. Grinchenko, D. G. Shevchenko, R. G. Averkin, V. N. Matz, S. Laukka and A. V. Korpusova, "A Subset of Cingulate Cortical Neurones Is Specifically Activated during Alcohol-Acquisition Behaviour," Acta Physiologica Scandinavica, Vol. 171, No. 1, 2001, pp. 87-97.

[47] Y. I. Alexandrov, Y. V. Grinchenko, V. N. Mats, S. Laukka and A. V. Korpusova, "Involvement of Rabbit Motor Cortex Neurons in the Instrumental Behavior before and after Chronic Ethanol Consumption: A comparison with the Limbic Cortex," I.P. Pavlov Journal of Higher Nervous Activity, Vol. 52, 2002, pp. 85-96. (In Russian)

[48] Y. I. Alexandrov, Y. V. Grinchenko, D. G. Shevchenko, V. N. Mats, S. Laukka and R. G. Averkin, "Neuron Activity in the Anterolateral Motor Cortex in Operant Food-Acquiring and Alcohol-Acquiring Behavior," Neuroscience and Behavioral Physiology, Vol. 35, No. 5, 2005, pp. 501-509. doi:10.1007/s11055-005-0085-2

[49] V. V. Gavrilov, Y. V. Grinchenko and Y. I. Alexandrov, "Comparison of the Sets of Behaviorally Specialized Limbic Cortex Neurons in Rats and Rabbits," Forum of European Neuroscience, Berlin EJN Abstract Book, Vol. 10, 1998, p. 154.

[50] J. Y. Chang, S. F. Sawyer, R. S. Lee and D. J. Woodward, "Electrophysiological and Pharmacological Evidence for the Role of the Nucleus Accumbens in Cocaine Self-Administration in Freely Moving Rats," Journal of Neuroscience, Vol. 14, No. 3, 1994, pp. 1224-1244.

[51] R. E. Hampson, J. D. Simeral and S. A. Deadwyler, "Distribution of Spatial and Nonspatial Information in Dorsal Hippocampus," Nature, Vol. 402, No. 6762, 1999, pp. 610-614. doi:10.1038/45154

[52] E. S. Luschei, C. R. Garthwaite and M. E. Armstrong, "Relationship of Firing Patterns of Units in Face Area of Monkey Precentral Cortex to Conditioned Jaw Movements," Journal of Neurophysiology, Vol. 34, No. 4, 1971, pp. 252-261.

[53] R. E. Martin, G. M. Murray, P. Kemppainen, Y. Masuda and B. J. Sessle, "Functional Properties of Neurons in the Primate Tongue Primary Motor Cortex during Swallowing," Journal of Neurophysiology, Vol. 78, No. 3, 1997, pp. 1516-1530.

[54] J. B. Ranck Jr., "Studies on Single Neurons in Dorsal Hippocampal Formation and Septum in Unrestrained Rats. I. Behavioral Correlates and Firing Repertoires," Experimental Neurology, Vol. 41, No. 2, 1973, pp. 461-531. doi:10.1016/0014-4886(73)90290-2

[55] K. Shima, K. Aya, H. Mushiake, M. Inase, H. Aizawa and J. Tanji, "Two Movement-Related Foci in the Primate Cingulate Cortex Observed in Signal-Triggered and SelfPaced Forelimb Movements," Journal of Neurophysiology, Vol. 65, No. 2, 1991, pp. 188-202.

[56] R. W. Stackman and J. S. Taube, "Firing Properties of Rat Lateral Mammillary Single Units: Head Direction, Head Pitch, and Angular Head Velocity," Journal of Neu- 
rophysiology, Vol. 18, No. 21, 1998, pp. 9020-9037.

[57] S. I. Wiener, "Spatial, Behavioral and Sensory Correlates of Hippocampal CA1 Complex Spike Cell Activity: Implications for Information Processing Functions," Progress in Neurobiology, Vol. 49, No. 4, 1996, pp. 335-361.

[58] S. I. Wiener, C. A. Paul and H. Eichenbaum, "Spatial and Behavioral Correlates of Hippocampal Neuronal Activity," Journal of Neuroscience, Vol. 9, No. 8, 1989, pp. 27372763.

[59] D. J. Woodward, P. H. Janak and J. Y. Chang, "Ethanol Action on Neural Networks Studied with Multineuron Recording in Freely Moving Animals," Alcoholism: Clinical \& Experimental Research, Vol. 22, No. 1, 1998, pp. 10-22. doi:10.1111/j.1530-0277.1998.tb03612.x

[60] Y. I. Alexandrov, "The Psychophsyiological Significance of Central and Peripheral Neuron Activity in Behavior," Nauka Press, Moscow, 1989.

[61] Y. I. Alexandrov, "Systemogeny and Neuronal Death," Neurochemistry, Vol. 21, 2004, pp. 5-14.

[62] A. G. Gorkin, K. G. Reymann and Y. I. Aleksandrov, "Long-Term Potentiation and Evoked Spike Responses in the Cingulate Cortex of Freely Mobile Rats," Neuroscience and Behavioral Physiology, Vol. 33, No. 8, 2003, pp. 763-772. doi:10.1023/A:1025189013402

[63] A. E. Ryabinin, K. R. Melia, M. Cole, F. E. Bloom and M. C. Wilson, "Alcohol Selectively Attenuates Stress-Induced c-fos Expression in Rat Hippocampus," Journal of Neuroscience, Vol. 15, No. 1, 1995, pp. 721-730.

[64] C. Vilpoux, V. Warnault, O. Pierrefiche, M. Daoust and M. Naassila, "Ethanol-Sensitive Brain Regions in Rat and Mouse: A Cartographic Review, Using Immediate Early Gene Expression," Alcoholism: Clinical \& Experimental Research, Vol. 33, No. 6, 2009, pp. 945-969. doi:10.1111/j.1530-0277.2009.00916.x

[65] N. Ludvig, B. T. Altura, S. E. Fox and B. M. Altura, "The Suppressant Effect of Ethanol, Delivered via Intrahippocampal Microdialysis, on the Firing of Local Pyramidal Cells in Freely Behaving Rats," Alcohol, Vol. 12, No. 5, 1995, pp. 417-421. doi:10.1016/0741-8329(95)00012-G

[66] S. C. Steffensen and S. J. Henriksen, "Comparison of the Effects of Ethanol and Chlordiazepoxide on Electrophysiological Activity in the Fascia Dentata and Hippocampus Regio Superior," Hippocampus, Vol. 2, No. 2, 1992, 201-211. doi:10.1002/hipo.450020210

[67] H. Yan, Q. Li, R. Madison, W. A. Wilson and H. S. Swartzwelder, "Differential Sensitivity of Hippocampal Interneurons to Ethanol in Adolescent and Adult Rats," Journal of Pharmacology and Experimental Therapeutics, Vol. 335, No. 1, 2010, pp. 51-60. doi:10.1124/jpet.110.168450

[68] F. Fadda and Z. L. Rossetti, "Chronic Ethanol Consumption: From Neuroadaptation to Neurodegeneration," Progress in Neurobiology, Vol. 56, No. 4, 1998, pp. 385-431. doi:10.1016/S0301-0082(98)00032-X

[69] D. W. Walker and B. E. Hunter, "Neuronal Adaptation in the Hippocampus Induced by Long-Term Ethanol Exposure," NIDA-Research Monographs, Vol. 78, 1987, pp. 108-131.
[70] T. Miki, S. J. Harris, P. A. Wilce, Y. Takeuchi and K. S. Bedi, "Effects of Alcohol Exposure during Early Life on Neuron Numbers in the Rat Hippocampus. I. Hilus Neurons and Granule Cells," Hippocampus, Vol. 13, No. 3, 2003, pp. 388-398. doi:10.1002/hipo.10072

[71] G. F. Koob and F. E. Bloom, "Cellular and Molecular Mechanisms of Drug Dependence," Science, Vol. 242, No. 4879,1988 , pp. 715-723. doi:10.1126/science. 2903550

[72] G. F. Koob, L. Stinus, M. Le Moal and F. E. Bloom, “Opponent Process Theory of Motivation: Neurobiological Evidence from Studies of Opiate Dependence," Neuroscience \& Biobehavioral Reviews, Vol. 13, No. 2-3, 1989, pp. 135-140. doi:10.1016/S0149-7634(89)80022-3

[73] K. V. Sudakov, "Motivation and Reinforcement in the Systemic Mechanisms of Behavior: Dynamic Reinforcement Engrams," Neuroscience and Behavioral Physiology, Vol. 26, No. 5, 1996, pp. 445-453. doi:10.1007/BF02359406

[74] K. V. Sudakov and A. V. Kotov, "Functional Transswitching of Dominant Motivation in the Systemic Organization of Behavioral Acts," Neuroscience and Behavioral Physiology, Vol. 17, No. 2, 1987, pp. 85-91. doi:10.1007/BF01184895

[75] P. J. Kenny, "Common Cellular and Molecular Mechanisms in Obesity and Drug Addiction," Nature Reviews Neuroscience, Vol. 12, No. 11, 2011, pp. 638-651. doi:10.1038/nrn3105

[76] N. D. Volkow, G. J. Wang, J. S. Fowler and F. Telang, "Overlapping Neuronal Circuits in Addiction and Obesity: Evidence of Systems Pathology," Philosophical Transactions of the Royal Society B: Biological Sciences, Vol. 363, No. 1507, 2008, pp. 3191-3200. doi:10.1098/rstb.2008.0107

[77] D. W. Walker, B. E. Hunter and W. C. Abraham, "Neuroanatomical and Functional Deficits Subsequent to Chronic Ethanol Administration in Animals," Alcoholism: Clinical \& Experimental Research, Vol. 5, No. 2, 1981, pp. 267-282. doi:10.1111/j.1530-0277.1981.tb04901.x

[78] T. K. Li, L. Lumeng, W. J. McBride, J. M. Murphy, J. C. Froehlich and S. Morzorati, "Pharmacology of Alcohol Preference in Rodents," Advances in Alcohol \& Substance Abuse, Vol. 7, No. 3-4, 1988, pp. 73-86. doi: $10.1300 / \mathrm{J} 251 \mathrm{v} 07 \mathrm{n} 0311$

[79] J. K. Chapin and D. J. Woodward, "Ethanol Withdrawal Increases Sensory Responsiveness of Single Somatosensory Cortical Neurons in the Awake, Behaving Rat," Alcoholism: Clinical \& Experimental Research, Vol. 13, No. 1, 1989, pp. 8-14. doi:10.1111/j.1530-0277.1989.tb00275.x

[80] J. M. Murphy, G. J. Gatto, W. J. McBride, L. Lumeng and T. K. Li, "Operant Responding for Oral Ethanol in the Alcohol-Preferring P and Alcohol-Nonpreferring NP Lines of Rats," Alcohol, Vol. 6, No. 2, 1989, pp. 127-131. doi:10.1016/0741-8329(89)90037-2

[81] R. L. McBride and W. R. Klemm, "Stereotaxic Atlas of Rabbit Brain Based on the Rapid Method of Photography of Frozen, Unstained Sections," Communications in 
Behavioral Biology, Vol. A2, 1968, pp. 179-215.

[82] Iu. V. Grinchenko and V. B. Shvyrkov, "A Simple Micromanipulator for Studying Neuronal Activity in Unrestrained Rabbits," I.P. Pavlov Journal of Higher Nervous Activity, Vol. 24, 1974, pp. 870-872. (In Russian)

[83] D. Ferster, "Is Neural Noise Just a Nuisance?" Science, Vol. 273, No. 5283, 1996, p. 1812. doi:10.1126/science.273.5283.1812

[84] E. Vaadia, I. Haalman, M. Abeles, H. Bergman, Y. Prut, H. Slovin and A. Aertsen, "Dynamics of Neuronal Interactions in Monkey Cortex in Relation to Behavioural Events," Nature, Vol. 373, No. 6514, 1995, pp. 515-518. doi: $10.1038 / 373515 \mathrm{a} 0$

[85] V. Burov Iu, A. B. Kampov-Polevoi and O. P. Kashevskaia, "Formation of Experimental Alcoholism in a Population of Crossbred Rats," Bulletin of Experimental Biology and Medicine, Vol. 96, 1983, pp. 67-68. (In Russian)

[86] J. O'Keefe, "Place Units in the Hippocampus of the Freely Moving Rat," Experimental Neurology, Vol. 51, No. 1, 1976, pp. 78-109. doi:10.1016/0014-4886(76)90055-8

[87] E. R. Wood, P. A. Dudchenko and H. Eichenbaum, "The Global Record of Memory in Hippocampal Neuronal Activity," Nature, Vol. 397, No. 6720, 1999, pp. 613-616. doi:10.1038/16564

[88] E. Pastalkova, V. Itskov, A. Amarasingham and G. Buzsaki, "Internally Generated Cell Assembly Sequences in the Rat Hippocampus," Science, Vol. 321, No. 5894, 2008, pp. 1322-1327. doi:10.1126/science. 1159775

[89] G. Buzsaki, "Hippocampus: Network Physiology," In: P. Shepherd and S. Grillner, Eds., Handbook of Brain Microcircuits, Oxford University Press, New York, 2010, pp. 165-174.

[90] V. V. Gavrilov, S. I. Wiener and A. Berthoz, "Discharge Correlates of Hippocampal Complex Spike Neurons in Behaving Rats Passively Displaced on a Mobile Robot," Hippocampus, Vol. 8, No. 5, 1998, pp. 475-490. doi:10.1002/(SICI)1098-1063(1998)8:5<475::AID-HIPO 7>3.0.CO;2-H

[91] O. Bengoechea and L. M. Gonzalo, "Effect of Chronic Alcoholism on the Human Hippocampus," Histology and Histopathology, Vol. 5, No. 3, 1990, pp. 349-357.

[92] P. A. McMullen, J. A. Saint-Cyr and P. L. Carlen, "Morphological Alterations in Rat CA1 Hippocampal Pyramidal Cell Dendrites Resulting from Chronic Ethanol Consumption and Withdrawal," Journal of Comparative Neurology, Vol. 225, No. 1, 1984, pp. 111-118. doi: $10.1002 /$ cne. 902250112

[93] T. Ribot, "Diseases of Memory," Appleton-Century Crofts, New York, 1882,

[94] M. A. King, B. E. Hunter and D. W. Walker, "Alterations and Recovery of Dendritic Spine Density in Rat Hippocampus Following Long-Term Ethanol Ingestion," Brain Research, Vol. 459, No. 2, 1988, pp. 381-385. doi:10.1016/0006-8993(88)90656-7

[95] M. M. Paula-Barbosa, F. Brandao, M. D. Madeira and A. Cadete-Leite, "Structural Changes in the Hippocampal Formation after Long-Term Alcohol Consumption and Withdrawal in the Rat," Addiction, Vol. 88, No. 2, 1993, pp. 237-247. doi:10.1111/j.1360-0443.1993.tb00807.x

[96] D. B. Matthews, "Ethanol and the Hippocampal System: Behaviour to Molecular Biology," Hippocampus, Vol. 10, No. 1, 2000, p. 87. doi:10.1002/(SICI)1098-1063(2000)10:1<87::AID-HIPO 9>3.0.CO;2-J

[97] J. Schummers and M. D. Browning, "Evidence for a Role for GABA(A) and NMDA Receptors in Ethanol Inhibition of Long-Term Potentiation," Molecular Brain Research, Vol. 94, No. 1-2, 2001, pp. 9-14. doi:10.1016/S0169-328X(01)00161-9

[98] T. P. Beresford, D. B. Arciniegas, J. Alfers, L. Clapp, B. Martin, Y. Du, D. Liu, D. Shen and C. Davatzikos, "Hippocampus Volume Loss Due to Chronic Heavy Drinking," Alcoholism: Clinical \& Experimental Research, Vol. 30, No. 11, 2006, pp. 1866-1870. doi:10.1111/j.1530-0277.2006.00223.x

[99] A. Cadete-Leite, M. A. Tavares, H. B. Uylings and M. Paula-Barbosa, "Granule Cell Loss and Dendritic Regrowth in the Hippocampal Dentate Gyrus of the Rat after Chronic Alcohol Consumption," Brain Research, Vol. 473, No. 1, 1988, pp. 1-14. doi:10.1016/0006-8993(88)90309-5

[100] D. G. Smith, J. E. Learn, W. J. McBride, L. Lumeng, T. K. Li and J. M. Murphy, "Long-Term Effects of Alcohol Drinking on Cerebral Glucose Utilization in Alcohol-Preferring Rats," Pharmacology Biochemistry and Behavior, Vol. 69, No. 3-4, 2001, pp. 543-553. doi:10.1016/S0091-3057(01)00553-6

[101] O. Bengoechea and L. M. Gonzalo, "Effects of Alcoholization on the Rat Hippocampus," Neuroscience Letters, Vol. 123, No. 2, 1991, pp. 112-114. doi:10.1016/0304-3940(91)90170-X

[102] H. G. Kuhn, H. Dickinson-Anson and F. H. Gage, "Neurogenesis in the Dentate Gyrus of the Adult Rat: Age-Related Decrease of Neuronal Progenitor Proliferation," Journal of Neuroscience, Vol. 16, No. 6, 1996, pp. 20272033.

[103] J. M. Parent, "Injury-Induced Neurogenesis in the Adult Mammalian Brain," Neuroscientist, Vol. 9, No. 4, 2003, pp. 261-272. doi:10.1177/1073858403252680

[104] C. D. Clelland, M. Choi, C. Romberg, G. D. Clemenson Jr., A. Fragniere, P. Tyers, S. Jessberger, L. M. Saksida, R. A. Barker, F. H. Gage and T. J. Bussey, "A Functional Role for Adult Hippocampal Neurogenesis in Spatial Pattern Separation," Science, Vol. 325, No. 5937, 2009, pp. 210-213. doi:10.1126/science.1173215

[105] E. Aberg, C. P. Hofstetter, L. Olson and S. Brene, "Moderate Ethanol Consumption Increases Hippocampal Cell Proliferation and Neurogenesis in the Adult Mouse," International Journal of Neuropsychopharmacology, Vol. 8, No. 4, 2005, pp. 557-567. doi:10.1017/S1461145705005286

[106] M. Nilsson, E. Perfilieva, U. Johansson, O. Orwar and P. S. Eriksson, "Enriched Environment Increases Neurogenesis in the Adult Rat Dentate Gyrus and Improves Spatial Memory," Journal of Neurobiology, Vol. 39, No. 4, 1999, pp. 569-578.

doi:10.1002/(SICI)1097-4695(19990615)39:4<569::AIDNEU10 $>3.0 . \mathrm{CO} ; 2-\mathrm{F}$ 
[107] P. S. Eriksson, E. Perfilieva, T. Bjork-Eriksson, A. M. Alborn, C. Nordborg, D. A. Peterson and F. H. Gage, "Neurogenesis in the Adult Human Hippocampus," Nature Medicine, Vol. 4, No. 11, 1998, pp. 1313-1317. doi: $10.1038 / 3305$

[108] E. Gould, A. Beylin, P. Tanapat, A. Reeves and T. J. Shors, "Learning Enhances Adult Neurogenesis in the Hippocampal Formation," Nature Neuroscience, Vol. 2, No. 3, 1999, pp. 260-265. doi:10.1038/6365

[109] F. T. Crews, K. Nixon and M. E. Wilkie, "Exercise Reverses Ethanol Inhibition of Neural Stem Cell Proliferation," Alcohol, Vol. 33, No. 1, 2004, pp. 63-71.

[110] J. N. Riley and D. W. Walker, "Morphological Alterations in Hippocampus after Long-Term Alcohol Consumption in Mice," Science, Vol. 201, No. 4356, 1978, pp. 646-648. doi:10.1126/science.566953

[111] M. M. Airaksinen and P. Peura, "Mechanisms of Alcohol Withdrawal Syndrome," Medical Biology, Vol. 65, No. 2-3, 1987, pp. 105-112.

[112] I. P. Anokhina, B. M. Kogan and A. Z. Drozdov, "Disturbances in Regulation of Catecholamine Neuromediation in Alcoholism," Alcohol, Vol. 23, No. 5, 1988, pp. 343350.

[113] B. S. Bratus, "Psychological Analysis of Personality Changes in Alcoholics," Edition of Moscow University, Moscow, 1974.

[114] R. J. Gibbins, H. Kalant, A. E. LeBlanc and J. W. Clark, "The Effects of Chronic Administration of Ethanol on Startle Thresholds in Rats," Psychopharmacologia, Vol. 19, No. 2, 1971, pp. 95-104. doi:10.1007/BF00402633

[115] B. Kissin, "The Pharmacodynamics and Natural History of Alcoholism," In: The Biology of Alcoholism, Plenum Press, New York, 1974, pp. 1-36.

[116] A. M. Ludwig, "Alcohol Input and Creative Output," British Journal of Addiction, Vol. 85, No. 7, 1990, pp. 953-963. doi:10.1111/j.1360-0443.1990.tb03726.x

[117] D. E. Feldman and M. Brecht, "Map Plasticity in Somatosensory Cortex," Science, Vol. 310, No. 5749, 2005, pp. 810-815. doi:10.1126/science. 1115807

[118] I. V. Bondar, D. A. Leopold, B. J. Richmond, J. D. Victor and N. K. Logothetis, "Long-Term Stability of Visual Pattern Selective Responses of Monkey Temporal Lobe Neurons," PLoS One, Vol. 4, No. 12, 2009, p. e8222. doi:10.1371/journal.pone.0008222

[119] P. M. Bradley, B. D. Burns, T. M. King and A. C. Webb, "Electrophysiological Correlates of Prior Training: An in Vitro Study of an Area of the Avian Brain Which Is Essential for Early Learning," Brain Research, Vol. 708, No. 1, 1996, pp. 100-107. doi:10.1016/0006-8993(95)01470-5

[120] M. Brecht, M. Scneider and I. Manns, "Silent Neurons in Sensorimotor Cortices: Implication for Cortical Plasticity," In: F. F. Ebner Ed., Neural Plasticity in Adult Somatic Sensory-Motor Systems, Taylor \& Francis Group, Boca Raton, 2005, pp. 1-19.

[121] P. A. Greenberg and F. A. Wilson, "Functional Stability of Dorsolateral Prefrontal Neurons," Journal of Neurophysiology, Vol. 92, No. 2, 2004, pp. 1042-1055. doi:10.1152/jn.00062.2004

[122] M. S. Jog, Y. Kubota, C. I. Connolly, V. Hillegaart and A. M. Graybiel, "Building Neural Representations of Habits," Science, Vol. 286, No. 5445, 1999, pp. 1745-1749. doi:10.1126/science.286.5445.1745

[123] M. A. Nicolelis, A. A. Ghazanfar, B. M. Faggin, S. Votaw and L. M. Oliveira, "Reconstructing the Engram: Simultaneous, Multisite, Many Single Neuron Recordings," Neuron, Vol. 18, No. 4, 1997, pp. 529-537. doi:10.1016/S0896-6273(00)80295-0

[124] E. M. Schmidt, M. J. Bak and J. S. McIntosh, "Long-Term Chronic Recording from Cortical Neurons," Experimental Neurology, Vol. 52, No. 3, 1976, pp. 496-506. doi:10.1016/0014-4886(76)90220-X

[125] H. A. Swadlow and T. P. Hicks, "Subthreshold Receptive Fields and Baseline Excitability of, 'Silent' S1 Callosal Neurons in Awake Rabbits: Contributions of AMPA/Kainate and NMDA Receptors," Experimental Brain Research, Vol. 115, No. 3, 1997, pp. 403-409. doi:10.1007/PL00005710

[126] L. T. Thompson and P. J. Best, "Long-Term Stability of the Place-Field Activity of Single Units Recorded from the Dorsal Hippocampus of Freely Behaving Rats," Brain Research, Vol. 509, No. 2, 1990, pp. 299-308. doi:10.1016/0006-8993(90)90555-P

[127] J. C. Williams, R. L. Rennaker and D. R. Kipke, "Stability of Chronic Multichannel Neural Recordings: Implications for a Long-Term Neural Interface," Neurocomputting, Vol. 26-27, 1999, pp. 1069-1076. doi:10.1016/S0925-2312(99)00106-X

[128] T. Xu, X. Yu, A. J. Perlik, W. F. Tobin, J. A. Zweig, K. Tennant, T. Jones and Y. Zuo, "Rapid Formation and Selective Stabilization of Synapses for Enduring Motor Memories," Nature, Vol. 462, 2009, pp. 915-919. doi:10.1038/nature08389

[129] M. A. Wilson and B. L. McNaughton, "Dynamics of the Hippocampal Ensemble Code for Space," Science, Vol. 261, No. 5124, 1993, pp. 1055-1058. doi:10.1126/science. 8351520

[130] G. Yang, F. Pan and W. B. Gan, "Stably Maintained Dendritic Spines Are Associated with Lifelong Memories," Nature, Vol. 462, No. 7275, 2009, pp. 920-924. doi:10.1038/nature 08577

[131] L. M. Frank, G. B. Stanley and E. N. Brown, "Hippocampal Plasticity across Multiple Days of Exposure to Novel Environments," Journal of Neuroscience, Vol. 24, No. 35, 2004, pp. 7681-7689. doi:10.1523/JNEUROSCI.1958-04.2004

[132] J. Epsztein, M. Brecht and A. K. Lee, "Intracellular Determinants of Hippocampal CA1 Place and Silent Cell Activity in a Novel Environment," Neuron, Vol. 70, No. 1, 2011, pp. 109-120. doi:10.1016/j.neuron.2011.03.006

[133] A. Carleton, L. T. Petreanu, R. Lansford, A. AlvarezBuylla and P. M. Lledo, "Becoming a New Neuron in the Adult Olfactory Bulb," Nature Neuroscience, Vol. 6, No. 5, 2003, pp. 507-518.

[134] T. J. Shors, G. Miesegaes, A. Beylin, M. Zhao, T. Rydel and E. Gould, "Neurogenesis in the Adult is Involved in 
the Formation of Trace Memories," Nature, Vol. 410, No. 6826, 2001, pp. 372-376. doi:10.1038/35066584

[135] J. A. Paton and F. N. Nottebohm, "Neurons Generated in the Adult Brain Are Recruited into Functional Circuits," Science, Vol. 225, No. 4666, 1984, pp. 1046-1048. doi:10.1126/science.6474166

[136] G. Kempermann, H. G. Kuhn and F. H. Gage, "Experience-Induced Neurogenesis in the Senescent Dentate Gyrus," Journal of Neuroscience, Vol. 18, No. 9, 1998, pp. 3206-3212.

[137] K. V. Anokhin, A. A. Tiunova and S. P. Rose, "Reminder Effects-Reconsolidation or Retrieval Deficit? Pharmacological Dissection with Protein Synthesis Inhibitors Following Reminder for a Passive-Avoidance Task in Young Chicks," European Journal of Neuroscience, Vol. 15 , No. 11, 2002, pp. 1759-1765. doi:10.1046/j.1460-9568.2002.02023.x

[138] O. E. Svarnik, T. A. Fadeeva, K. V. Anokhin and Y. I. Alexandrov, "Learning Strategies and c-Fos Expression in the Rat Retrosplenial Cortex during Operant Skill Acquisition," FENS Abstracts, Vol. 4, 2008.

[139] M. A. Castro-Alamancos, J. Borrell and L. M. GarciaSegura, "Performance in an Escape Task Induces FosLike Immunoreactivity in a Specific Area of the Motor Cortex of the Rat," Neuroscience, Vol. 49, No. 1, 1992, 157-162. doi:10.1016/0306-4522(92)90083-E

[140] E. M. Bowman, T. G. Aigner and B. J. Richmond, "Neural Signals in the Monkey Ventral Striatum Related to Motivation for Juice and Cocaine Rewards," Journal of Neurophysiology, Vol. 75, No. 3, 1996, pp. 1061-1073.

[141] R. M. Carelli and S. A. Deadwyler, "Cellular Mechanisms Underlying Reinforcement-Related Processing in the $\mathrm{Nu}-$ cleus Accumbens: Electrophysiological Studies in Behaving Animals," Pharmacology Biochemistry and Behavior, Vol. 57, No. 3, 1997, pp. 495-504. doi:10.1016/S0091-3057(96)00442-X

[142] K. M. Kendrick and B. A. Baldwin, "The Effects of Sodium Appetite on the Responses of Cells in the Zona Incerta to the Sight or Ingestion of Food, Salt and Water in Sheep," Brain Research, Vol. 492, No. 1-2, 1989, pp. 211-218. doi:10.1016/0006-8993(89)90903-7

[143] D. L. Robinson and R. M. Carelli, "Distinct Subsets of Nucleus Accumbens Neurons Encode Operant Responding for Ethanol versus Water," European Journal of Neuroscience, Vol. 28, No. 9, 2008, pp. 1887-1894. doi:10.1111/j.1460-9568.2008.06464.x

[144] J. A. Ainge, M. Tamosiunaite, F. Woergoetter and P. A. Dudchenko, "Hippocampal CA1 Place Cells Encode Intended Destination on a Maze with Multiple Choice Points," Journal of Neuroscience, Vol. 27, No. 36, 2007, pp. 9769-9779. doi:10.1523/JNEUROSCI.2011-07.2007

[145] C. R. Breese, R. E. Hampson and S. A. Deadwyler, "Hippocampal Place Cells: Stereotypy and Plasticity," Journal of Neuroscience, Vol. 9, 1989, 1097-1111.

[146] P. J. Best and A. M. White, "Hippocampal Cellular Activity: A Brief History of Space," Proceedings of the National Academy of Sciences, Vol. 95, No. 6, 1998, pp. 2717-2719. doi:10.1073/pnas.95.6.2717
[147] P. J. Best, A. M. White and A. Minai, "Spatial Processing in the Brain: The Activity of Hippocampal Place Cells," Annual Review of Neuroscience, Vol. 24, No. 1, 2001, pp. 459-486. doi:10.1146/annurev.neuro.24.1.459

[148] T. Kobayashi, H. Nishijo, M. Fukuda, J. Bures and T. Ono, "Task-Dependent Representations in Rat Hippocampal place Neurons," Journal of Neurophysiology, Vol. 78, No. 2, 1997, pp. 597-613.

[149] E. J. Markus, Y. L. Qin, B. Leonard, W. E. Skaggs, B. L. McNaughton and C. A. Barnes, "Interactions between Location and Task Affect the Spatial and Directional Firing of Hippocampal Neurons," Journal of Neuroscience, Vol. 15, No. 11, 1995, pp. 7079-7094.

[150] I. Lee and J. Kim, “The Shift from a Response Strategy to Object-in-Place Strategy during Learning Is Accompanied by a Matching Shift in Neural Firing Correlates in the Hippocampus," Learning \& Memory, Vol. 17, No. 8, 2010, pp. 381-393. doi:10.1101/1m.1829110

[151] P. J. Kennedy and M. L. Shapiro, "Motivational States Activate Distinct Hippocampal Representations to Guide Goal-Directed Behaviors," Proceedings of the National Academy of Sciences, Vol. 106, No. 26, 2009, pp. 1080510810. doi:10.1073/pnas.0903259106

[152] L. Zinyuk, S. Kubik, Y. Kaminsky, A. A. Fenton and J. Bures, "Understanding Hippocampal Activity by Using Purposeful Behavior: Place Navigation Induces Place Cell Discharge in Both Task-Relevant and Task-Irrelevant Spatial Reference Frames," Proceedings of the National Academy of Sciences, Vol. 97, No. 7, 2000, pp. 3771-3776. doi:10.1073/pnas.97.7.3771

[153] M. A. Moita, S. Rosis, Y. Zhou, J. E. LeDoux and H. T. Blair, "Putting Fear in Its Place: Remapping of Hippocampal Place Cells during Fear Conditioning," Journal of Neuroscience, Vol. 24, No. 31, 2004, pp. 7015-7023. doi:10.1523/JNEUROSCI.5492-03.2004

[154]E. R. Wood, P. A. Dudchenko, R. J. Robitsek and H. Eichenbaum, "Hippocampal Neurons Encode Information about Different Types of Memory Episodes Occurring in the Same Location," Neuron, Vol. 27, No. 3, 2000, pp. 623-633. doi:10.1016/S0896-6273(00)00071-4

[155] A. J. Robison and E. J. Nestler, "Transcriptional and Epigenetic Mechanisms of Addiction," Nature Reviews Neuroscience, Vol. 12, No. 11, 2011, pp. 623-637. doi: $10.1038 / \mathrm{nrn} 3111$

[156] S. S. Schreiber and M. Baudry, "Selective Neuronal Vulnerability in the Hippocampus-A Role for Gene Expression?" Trends in Neurosciences, Vol. 18, No. 10, 1995 , pp. 446-451. doi:10.1016/0166-2236(95)94495-Q

[157] V. V. Sherstnev, V. V. Iurasov, Z. I. Storozheva, M. A. Gruden and N. E. Iakovleva, "Biochemical Markers of Apoptosis in Different Brain Regions after Training," I.P. Pavlov Journal of Higher Nervous Activity, Vol. 55, 2005, pp. 729-733. (In Russian)

[158] C. H. Bailey and E. R. Kandel, "Structural Changes Accompanying Memory Storage," Annual Review of Physiology, Vol. 55, No. 1, 1993, pp. 397-426. doi:10.1146/annurev.ph.55.030193.002145

[159] S. Pulipparacharuvil, W. Renthal, C. F. Hale, M. Tanigu- 
chi, G. Xiao, A. Kumar, S. J. Russo, D. Sikder, C. M. Dewey, M. M. Davis, P. Greengard, A. C. Nairn, E. J. Nestler and C. W. Cowan, "Cocaine Regulates MEF2 to Control Synaptic and Behavioral Plasticity," Neuron, Vol. 59, No. 4, 2008, pp. 621-633. doi:10.1016/j.neuron.2008.06.020

[160] V. Deroche-Gamonet, D. Belin and P. V. Piazza, "Evidence for Addiction-Like Behavior in the Rat," Science, Vol. 305, No. 5686, 2004, pp. 1014-1017.

doi:10.1126/science. 1099020 